\title{
Transcriptomic characterization of the enzymatic antioxidants FeSOD, MnSOD, APX and KatG in the dinoflagellate genus Symbiodinium
}

Thomas Krueger ${ }^{1,2^{*}}$, Paul L Fisher ${ }^{1,3}$, Susanne Becker ${ }^{1}$, Stefanie Pontasch ${ }^{1}$, Sophie Dove ${ }^{4}$, Ove Hoegh-Guldberg ${ }^{5}$, William Leggat ${ }^{6}$ and Simon K Davy ${ }^{1 *}$

\begin{abstract}
Background: The diversity of the symbiotic dinoflagellate Symbiodinium sp., as assessed by genetic markers, is well established. To what extent this diversity is reflected on the amino acid level of functional genes such as enzymatic antioxidants that play an important role in thermal stress tolerance of the coral-Symbiodinium symbiosis is, however, unknown. Here we present a predicted structural analysis and phylogenetic characterization of the enzymatic antioxidant repertoire of the genus Symbiodinium. We also report gene expression and enzymatic activity under short-term thermal stress in Symbiodinium of the B1 genotype.

Results: Based on eight different ITS2 types, covering six clades, multiple protein isoforms for three of the four investigated antioxidants (ascorbate peroxidase [APX], catalase peroxidase [KatG], manganese superoxide dismutase [MnSOD]) are present in the genus Symbiodinium. Amino acid sequences of both SOD metalloforms (Fe/Mn), as well as KatG, exhibited a number of prokaryotic characteristics that were also supported by the protein phylogeny. In contrast to the bacterial form, KatG in Symbiodinium is characterized by extended functionally important loops and a shortened C-terminal domain. Intercladal sequence variations were found to be much higher in both peroxidases, compared to SODs. For APX, these variable residues involve binding sites for substrates and cofactors, and might therefore differentially affect the catalytic properties of this enzyme between clades. While expression of antioxidant genes was successfully measured in Symbiodinium B1, it was not possible to assess the link between gene expression and protein activity due to high variability in expression between replicates, and little response in their enzymatic activity over the three-day experimental period.
\end{abstract}

Conclusions: The genus Symbiodinium has a diverse enzymatic antioxidant repertoire that has similarities to prokaryotes, potentially as a result of horizontal gene transfer or events of secondary endosymbiosis. Different degrees of sequence evolution between SODs and peroxidases might be the result of potential selective pressure on the conserved molecular function of SODs as the first line of defence. In contrast, genetic redundancy of hydrogen peroxide scavenging enzymes might permit the observed variations in peroxidase sequences. Our data and successful measurement of antioxidant gene expression in Symbiodinium will serve as basis for further studies of coral health.

Keywords: Oxidative stress, ROS, Coral reefs, Catalase peroxidase, Superoxide dismutase, Ascorbate peroxidase, Antioxidant gene expression

\footnotetext{
*Correspondence: thomas.krueger@epfl.ch; simon.davy@vuw.ac.nz

'School of Biological Sciences, Victoria University of Wellington, Wellington

6140, New Zealand

${ }^{2}$ Laboratory for Biological Geochemistry, ENAC, École polytechnique fédérale

de Lausanne (EPFL), Lausanne 1015, Switzerland

Full list of author information is available at the end of the article
}

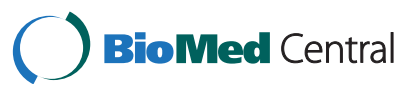

(c) 2015 Krueger et al.; licensee BioMed Central. This is an Open Access article distributed under the terms of the Creative Commons Attribution License (http://creativecommons.org/licenses/by/4.0), which permits unrestricted use, distribution, and reproduction in any medium, provided the original work is properly credited. The Creative Commons Public Domain Dedication waiver (http://creativecommons.org/publicdomain/zero/1.0/) applies to the data made available in this article, unless otherwise stated. 


\section{Background}

The photosynthetic dinoflagellate Symbiodinium sp. is a significant endosymbiont of a wide range of marine invertebrates and is a major contributor to the ecological success of reef-building corals in shallow tropical seas $[1,2]$. In vitro cultivation of coral symbionts allowed their identification as gymnoid dinoflagellates and led to their description as Symbiodinium microadriaticum in the middle of the $20^{\text {th }}$ century [3-5]. However, subsequent studies on cellular ultrastructure, cell morphology and physiological features suggested that Symbiodinium microadriaticum might in fact represent more than one species $[6,7]$. Through the application of molecular genetic tools, the genus Symbiodinium was revealed to contain a high degree of diversity, where genetic distances between Symbiodinium taxa are greater than between orders of non-symbiotic dinoflagellates [8-10]. Currently, nine major Symbiodinium clades (A-I), based on nuclear ribosomal DNA sequences and chloroplast $23 \mathrm{~S}$ rDNA are established [11]. With the exception of clade E, multiple Symbiodinium types are recognized within each clade (e.g., A1, C3, F1), primarily based on sequence variations in the faster evolving internal transcribed spacer region 2 (ITS2) [11,12]. The now established phylogenetic relationship that designates main Symbiodinium clades and types within each clade is well supported by a number of different genetic markers [13-16]. Due to the multicopy nature of ITS2 and the resulting intragenomic variation, the application of an operational taxonomic unit (OTU) framework based on a statistical cluster-based approach with defined cut-offs, might be the closest approximation of a species definition in the genus Symbiodinium to date $[17,18]$. For important Symbiodinium clades, such as clade $\mathrm{C}$ that represents the major clade in Indo-Pacific corals, some authors have provided support that ITS2 types indeed represent evolutionarily distinct species by complementing the phylogenetic analysis with ecological, geographic and population genetic data $[19,20]$.

The environmental sensitivity of the mutualistic association between Symbiodinium types and scleractinian corals has gained considerable attention over the last few decades through the phenomenon of coral bleaching. Bleaching results from a decline in endosymbiont density and/or photosynthetic pigment content in response to environmental stress, causing a paling of the coral [21], and can potentially lead to death of the coral colony. Large scale coral bleaching with subsequent mortality as a result of climate change-induced warming of the oceans represents a major threat to the functioning of coral reef ecosystems [22,23].

Variability in bleaching susceptibility and severity between different coral-Symbiodinium associations under similar temperature regimes has highlighted the role of Symbiodinium diversity in determining the performance of the coral "holobiont" (i.e., the entire community of living organisms that inhabit a coral colony [24-27]). While the physiological mechanisms of bleaching are not yet fully understood, the generation of reactive oxygen species (ROS) in the symbiont population under stress is thought to play an important role in the cellular bleaching cascade $[28,29]$. In this context, differences in ROS generation or antioxidant defences between different Symbiodinium types might contribute to the varying bleaching susceptibility between different coral species or even between populations of the same species.

Potentially damaging ROS, such as superoxide $\left(\mathrm{O}_{2}^{\bullet-}\right)$ or hydrogen peroxide $\left(\mathrm{H}_{2} \mathrm{O}_{2}\right)$, occur as side-products of photosynthesis and respiration [30], and antioxidants play an important role in preventing oxidative damage and, more generally, in maintaining redox homeostasis. The concerted response of the antioxidant network involves a number of pathways, and the scavenging of superoxide by superoxide dismutase (SOD) is considered the first line of defence. SOD is expressed in a number of metalloforms of which some are organellespecific in higher plants (e.g., mitochondrial MnSOD or chloroplastic FeSOD; [31]). Downstream defences, such as peroxidases and catalases, deal with the end product of SOD activity, hydrogen peroxide. The activity of these peroxidases is linked to the availability of low molecular weight antioxidants, such as ascorbate and glutathione, which act as important cofactors and are essential to the $\mathrm{H}_{2} \mathrm{O}_{2}$ metabolism of photosynthetic organisms [32].

Changes in activity of SOD, ascorbate peroxidase (APX) and the bacterially-derived enzyme catalase peroxidase (KatG) have all been shown to be involved in the response to light and temperature stress in populations of both cultured and in hospite Symbiodinium [33-37]. Information on the protein structure and regulation of antioxidant gene expression, however, has been largely limited by a lack of nucleic acid sequence data, though the first steps towards this have been undertaken [38]. The application of Sanger sequencing and high-throughput sequencing technologies to the coral-dinoflagellate symbiosis has now provided a large body of transcriptomic data for a number of coral species [39-44], but only for a few Symbiodinium types [45-48]. The responses of a number of oxidative stress-targeted genes, such as ferritin, heat shock proteins, glutathione $\mathrm{S}$-transferase, MnSOD and catalase have been documented in coral hosts exposed to environmental stress [44,49-52], though the mRNA expression of only one antioxidant gene $(a p x 1)$ has been quantified in Symbiodinium (clade C only) [53,54]. Considering their pivotal role in coral biology, it is essential to broaden the transcriptomic toolkit to allow the assessment of antioxidant expression patterns in a variety of different Symbiodinium types. 
The focus of this study was therefore to compile and characterize gene transcripts from four major enzymatic antioxidants (FeSOD, MnSOD, APX, and KatG) from different Symbiodinium clades. A more thorough analysis was done within clade $\mathrm{C}$ specifically, by looking at sequence similarities between ITS2 types. Degrees of sequence variation at the amino acid level, as well as phylogenetic relationships across different clades, were investigated. Furthermore, we demonstrated the utility of these data by measuring antioxidant gene expression and its corresponding enzyme activity in Symbiodinium B1 under short-term thermal stress.

\section{Results}

\section{Transcriptomic characterization of antioxidants}

A total of 87 antioxidant sequences, covering Symbiodinium clades A-F, revealed the presence of at least seven APX isoforms, four MnSOD isoforms, two KatG isoforms and one FeSOD form (Table 1).

\section{Superoxide dismutases}

Both, MnSOD and FeSOD represent dimeric forms that were highly conserved across clades. Transcripts of fesod were only successfully amplified from Symbiodinium B1, $E$ and F1, while none were found in any of the available EST libraries. Obtained partial sequences of Symbiodinium FeSOD (SymFeSOD) covered 66-74\% of the encoded total protein length of 201 aa $(21.9 \mathrm{kDa})$, as determined from a previously published Symbiodinium clade A sequence (PF-2005; [GenBank:AY916504]) (Figure 1). Encoded protein sequence length within each MnSOD isoform was similar across clades (within 1-9 aa of each other), but absolute length between isoforms varied by up to 19\% (e.g., SymMnSOD3 vs. SymMnSOD2). Mean pairwise protein identities across clades were highest for SymFeSOD $(96 \% \pm 2 \%$; mean \pm SD), SymMnSOD1 $(94 \% \pm 2 \%)$, and SymMnSOD2 $(90 \% \pm 3 \%)$, with near identical amino acid sequences (96-97\%) for MnSOD1 within clade C (C1, C3, C15) (Figure 1, Additional file 1). The predicted tertiary monomer structure of SymMnSOD1 from Symbiodinium B1 and C1 was also highly similar (Figure 2). I-tasser modelling returned bacterial SODs as the top five structural Protein Data Bank (PDB) analogues for both types. Pairwise identities between clades were lower for SymMnSOD3 (73\% A1 vs. D) and other MnSOD (41\%) sequences, partially due to limited sequence data for the latter ones (Figure 1, Additional file 1). The lowest pairwise identities between full-length sequences were usually encountered between Symbiodinium of clade $\mathrm{D}$ and all other clades (e.g., 87-89\% D vs. B1 and F1 for MnSOD2; 73\% D vs. A1 for MnSOD3).

Dinoflagellate spliced leader sequences were located 45-53 bp upstream of the start codons of SymMnSODs. Signal peptides, but no transmembrane domains were found in all N-terminal domains (Additional file 2). However, prediction strength of their subcellular locations given by TargetP 1.1 was low for SymMnSOD1 and 2 (reliability class 3-5), assigning them to the mitochondrial or secretory pathway (Table 1 ). The remaining MnSOD isoforms were identified as part of the secretory pathway. Variants of the prominent ancient plastid-targeting "FVAP"-type motif ("FVSP" in MnSOD1 + 2) were found in the transit peptide region of almost all sequences (Additional file 2). No signal peptide was found for SymFeSOD.

\section{Ascorbate peroxidase}

A total of $46 a p x$ sequences were obtained from PCR amplifications and EST library entries, and they were grouped according to their amino acid sequence characteristics (SymAPX1-SymAPX6) as long as members of these six groups were found in at least two Symbiodinium clades (Table 1). SymAPX1 and 2 were identified as hybrid ascorbate-cytochrome $c$ peroxidases (APX-CcP), whereas all others matched common ascorbate peroxidase sequences (Additional file 3). N-terminal signal peptides were only found in SymAPX2 and 6, and two unclassified sequences, assigning SymAPX2 and 6 to either secretory or mitochondrial pathways (Table 1, Additional file 4). TargetP did not recognize the Phobius-predicted signal peptide in the two unclassified sequences. All other APX sequences appear to be cytosolic. Overall protein length varied considerably between cytosolic isoforms (308-453 aa), and multiple start codons could be found within the same ORF. Nevertheless, ATGpr software's prediction of the "true" start codon in SymAPX1 was supported by the location of the spliced leader, found 58 bp upstream of the coding sequence in the SymAPX1 isoform of Symbiodinium F1 (Mv). This was, however, the only APX sequence where the spliced leader primer, in conjunction with a reverse primer, successfully amplified a gene fragment.

Length differences between APX isoforms (relative to SymAPX1) were driven by a number of deletions in the $\mathrm{N}$-terminal domain (SymAPX2-6) and between residues 397-418 (SymAPX3-5), but also by large insertions around residues 275-302 (SymAPX3-5) and 339-371 (SymAPX3-6) (Figure 3). Pairwise amino acid identities were considerably lower than for SODs, but varied depending on isoform. Full-length comparison of SymAPX1 showed pairwise identities of $63-64 \%$ (A1 vs. B1), 64-67\% (A1 vs. C3) and 76\% (B1 vs. C3), or even lower values (e.g., 56-62\% for A1 vs. F1 [Additional file 5]). In comparison, the similarities of SymAPX3 between A1 and D were 73-74\%. Variation in SymAPX1 within clade $C$ was predominantly found in $\mathrm{C} 15$ (91\% pairwise identity to $\mathrm{C} 1$ and $\mathrm{C} 3$ ), whereas $\mathrm{C} 1$ and C3 were nearly identical (99.6-100\%). Functionally important residues involved in binding of heme and hydrogen peroxide, as well as the formation of the catalytic site, were largely conserved within each APX isoform, 
Table 1 Characteristics of isoforms of four enzymatic antioxidants in Symbiodinium

\begin{tabular}{|c|c|c|c|c|c|c|c|c|c|c|c|}
\hline Isoform & \# of sequences & $\begin{array}{l}\text { Identical } \\
\text { sites }\end{array}$ & $\begin{array}{l}\text { Clades } \\
\text { represented }\end{array}$ & $\begin{array}{l}\text { \# of sequences } \\
\text { with N-termini }\end{array}$ & $\begin{array}{l}\text { Subcellular } \\
\text { location* }\end{array}$ & $\begin{array}{l}\text { TargetP reliability } \\
\text { class [PLANT] }\end{array}$ & $\begin{array}{l}\text { TargetP reliability } \\
\text { class [NON-PLANT] }\end{array}$ & $\begin{array}{l}\text { \# of full length } \\
\text { sequences }\end{array}$ & $\begin{array}{l}\text { Ungapped } \\
\text { length [aa] }\end{array}$ & $\begin{array}{l}\text { Predicted molecular } \\
\text { weight }^{\ddagger}[\mathrm{kDa}]\end{array}$ & $\begin{array}{l}\text { Predicted GPI-anchor } \\
\text { [GPI-SOM/PredGPI] }\end{array}$ \\
\hline SymMnSOD1 & 6 & $89.1 \%$ & $B, C$ & 5 & $M / S^{1}$ & M4-5; S3 & M4-5; S3-5 & 4 & $263-265$ & $28.6-28.9$ & No/No \\
\hline SymMnSOD2 & 4 & $84.9 \%$ & $B, D, F$ & 4 & $M / S^{2}$ & M5; S5 & M3-5; S3 & 4 & 294-303 & $32.0-32.6$ & No/No \\
\hline SymMnSOD3 & 5 & $\begin{array}{l}55.5 \% \\
\left(73.3 \%^{3}\right)\end{array}$ & $A, B, D$ & 3 & S & S2-3 & S1-2 & 2 & $246-247$ & $26.5-27.2$ & No/No \\
\hline $\begin{array}{l}\text { SymMnSOD } \\
\text { (others) }\end{array}$ & 6 & & $A, B$ & 5 & $\mathrm{~S}$ & S2-3 & S1-3 & 1 & 270 & 29.2 & No/No \\
\hline SymFeSOD & 4 & $92.7 \%$ & $A, B, E, F$ & 1 & C & - & - & 1 & 201 & 21.9 & No/No \\
\hline SymAPX1 & 23 & $26.1 \%$ & $A, B, C, D, F$ & 14 & C & - & - & 6 & 391-397 & $42.4-43.6$ & $\mathrm{No} / \mathrm{No}$ \\
\hline SymAPX2 & 7 & $67.1 \%$ & $A, B, C, D$ & 2 & $\mathrm{M}^{4} / \mathrm{S}^{5}$ & $\mathrm{M} 5 ; \mathrm{S} 1$ & $\mathrm{M} 4 ; \mathrm{S} 1$ & 2 & $311 / 362$ & $33.9 / 38.6$ & No/No \\
\hline SymAPX3 & 6 & $69.5 \%$ & $A, D$ & 5 & C & - & - & 4 & $317-320$ & $34.7-34.9$ & No/No \\
\hline SymAPX4 & 3 & $87.3 \%$ & $B, D, F$ & 1 & C & - & - & 1 & 308 & 33.6 & No/No \\
\hline SymAPX5 & 3 & $86.1 \%$ & $A, D$ & 2 & C & - & - & 2 & 453 & 49.0/49.1 & No/No \\
\hline SymAPX6 & 2 & $69.2 \%$ & $A, B$ & 1 & M & M5 & S5 & 1 & 328 & 36.0 & $\mathrm{Yes}^{7} / \mathrm{No}$ \\
\hline $\begin{array}{l}\text { SymAPX } \\
\text { (others) }\end{array}$ & 2 & & A & 2 & $?$ & Not recognized & Not recognized & 0 & - & - & \\
\hline SymKatG1 & 12 & $63.6 \%$ & $\begin{array}{l}A, B, C, D, \\
E, F\end{array}$ & 5 & $\mathrm{~S}$ & S2-5 & S1-S5 & 1 & 486 & 54.4 & Uncertain ${ }^{7} / \mathrm{No}$ \\
\hline SymKatG2 & 4 & $73.1 \%$ & $A, B, D$ & 3 & $\mathrm{M}^{6} / \mathrm{S}$ & M4; S5 & S2-3 & 1 & 423 & 46.7 & $\mathrm{No} / \mathrm{No}$ \\
\hline
\end{tabular}

Molecular characterization of superoxide dismutase (FeSOD/MnSOD), ascorbate peroxidase (APX), and catalase peroxidase (KatG) protein isoforms identified in the genus Symbiodinium. Proportion of identical residues across represented clades is indicated for each isoform (for pairwise identities between types see Additional files 1,5 and 7). Subcellular location indicated as cytosolic (C), mitochondrial (M), or as part of the secretory pathway (S). TargetP reliability classes (1-5) are indicated, where 1 indicates the strongest prediction. Length, molecular weights, and presence of GPI anchor are based on full-length sequences.

"based on results with "PLANT" settings in TargetP 1.1. for all sequences with complete N-terminal domains.

${ }^{\ddagger}$ weights for SOD metalloforms and KatG refer to the monomer.

'only Symbiodinium C15 M. digitata SymMnSOD1.

2only Symbiodinium B1 Mf1.05b SymMnSOD2 rep_c13368 and Symbiodinium of clade D A. hyacinthus SymMnSOD2 [GenBank:GAFP01017905].

${ }^{3}$ including Symbiodinium A1 CCMP2467 SymMnSOD3 Assembly2 sequence.

${ }_{5}^{4}$ Symbiodinium of clade D A. hyacinthus SymAPX2 [GenBank:GAFP01018157].

${ }^{5}$ Symbiodinium of clade D A. hyacinthus SymAPX2 [GenBank:GAFP01007188].

${ }^{6}$ Symbiodinium of clade D A. hyacinthus SymKatG2 [GenBank:GAFP01010883].

7 GPI-SOM results based on C\&N-terminal signal. 


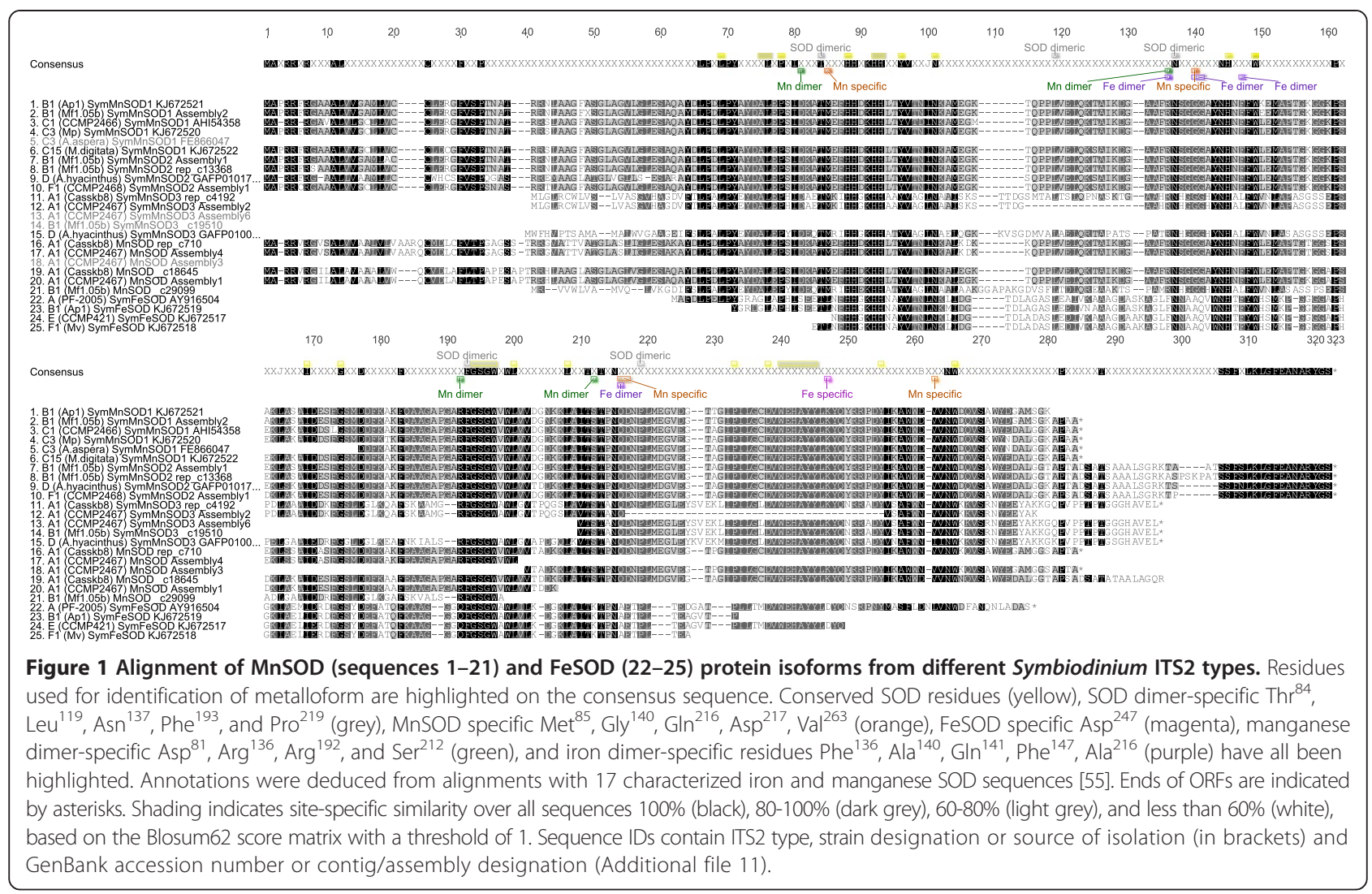

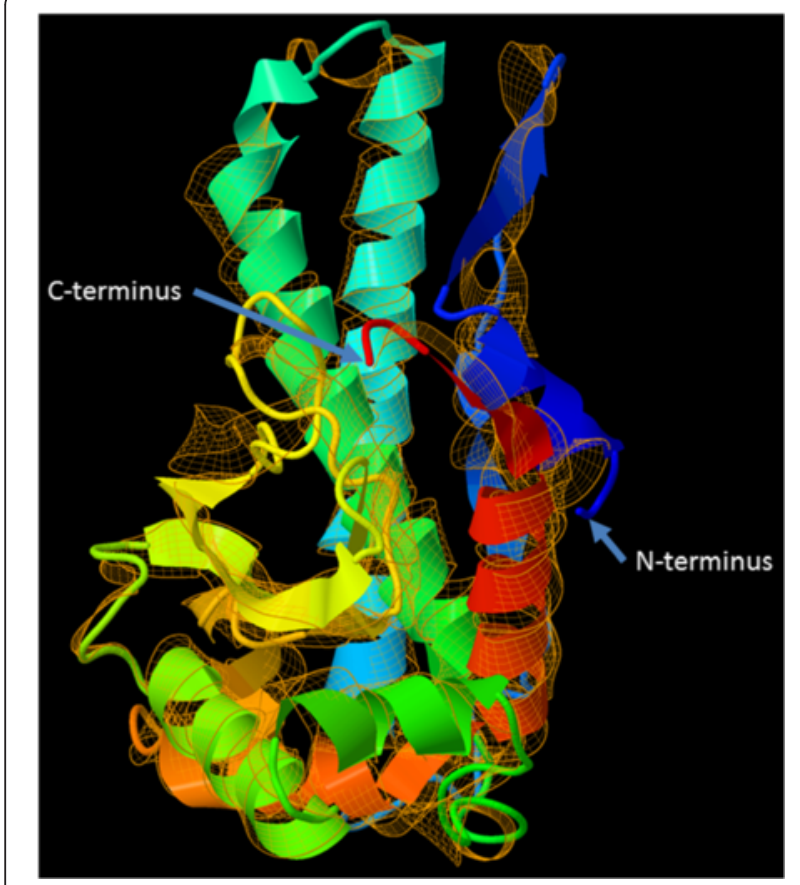

Figure 2 Superimposition of SymMnSOD1 from Symbiodinium B1 and C1. Shown are the predicted mature monomer structures of SymMnSOD1 from Symbiodinium B1 (Ap1, solid, C-score $=0.30$ ) and Symbiodinium C1 (CCMP2466, orange mesh ribbon, $C$-score $=0.32$ ). Colour temperature indicates direction from the $\mathrm{N}$ - to the $\mathrm{C}$-terminus (blue to red). with the exceptions of Symbiodinium C15 and F1, where $\operatorname{Trp}^{175}$ and His ${ }^{176}$ in the hydrogen peroxide binding site of SymAPX1 were replaced by Phe ${ }^{175}$ in $\mathrm{C} 15$ and $\mathrm{Asn}^{176}$ in both (Figures 3 and 4). In Symbiodinium F1 (Mv), five of the seven ascorbate binding site residues and two of the six heme binding site residues differed from those of other clades.

\section{Catalase peroxidase}

The two KatG isoforms found in Symbiodinium differed mainly by two insertions in SymKatG1 between the consensus residues 88-95, 202-228 and 321-334 (Figure 5). The proximal heme-ligand signature motif (TVALIGGGHTL; Prosite PS00435) differed slightly between both isoforms, but was highly conserved in each one. Signal peptides for the secretory (SymKatG1 and SymKatG2) and/or mitochondrial pathway (D [Acropora hyacinthus] SymKatG2 [GenBank:GAFP01010883]) were found (Table 1, Additional file 6). TargetP reliability of the assigned pathway was, however, highly variable between sequences. Mean pairwise identities across clades was $80 \% \pm 9 \%$ for SymKatG1 (clades A-F) and 77\% $\pm 2 \%$ for SymKatG2 (clades A, B, D), respectively. Symbiodinium $\mathrm{C} 1$ and $\mathrm{C} 3$ shared the highest pairwise identity (98.1\% for SymKatG1; Additional file 7).

Comparison with bacterial KatGs revealed that SymKatGs are, in general, shorter and cover only the N-terminal 


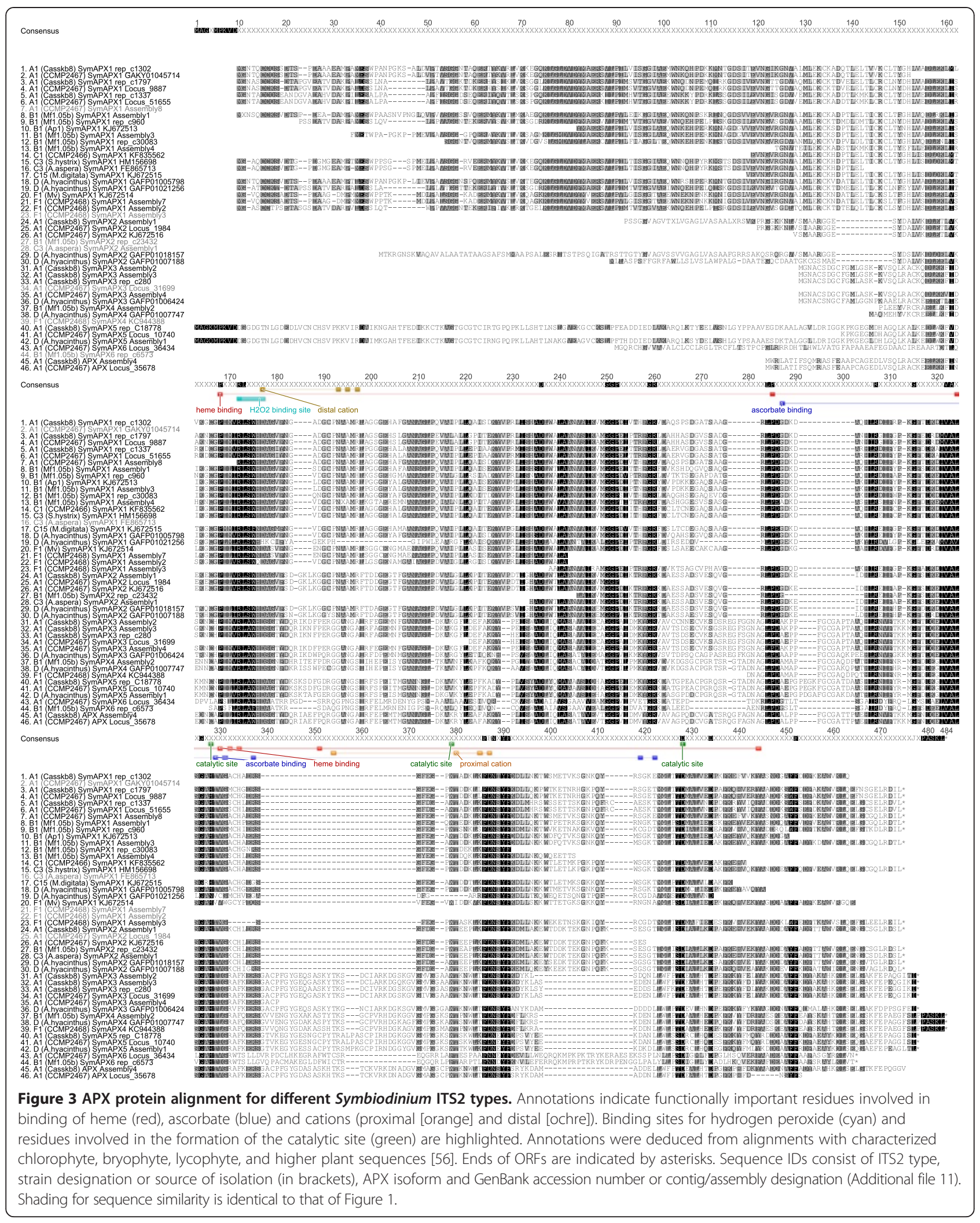



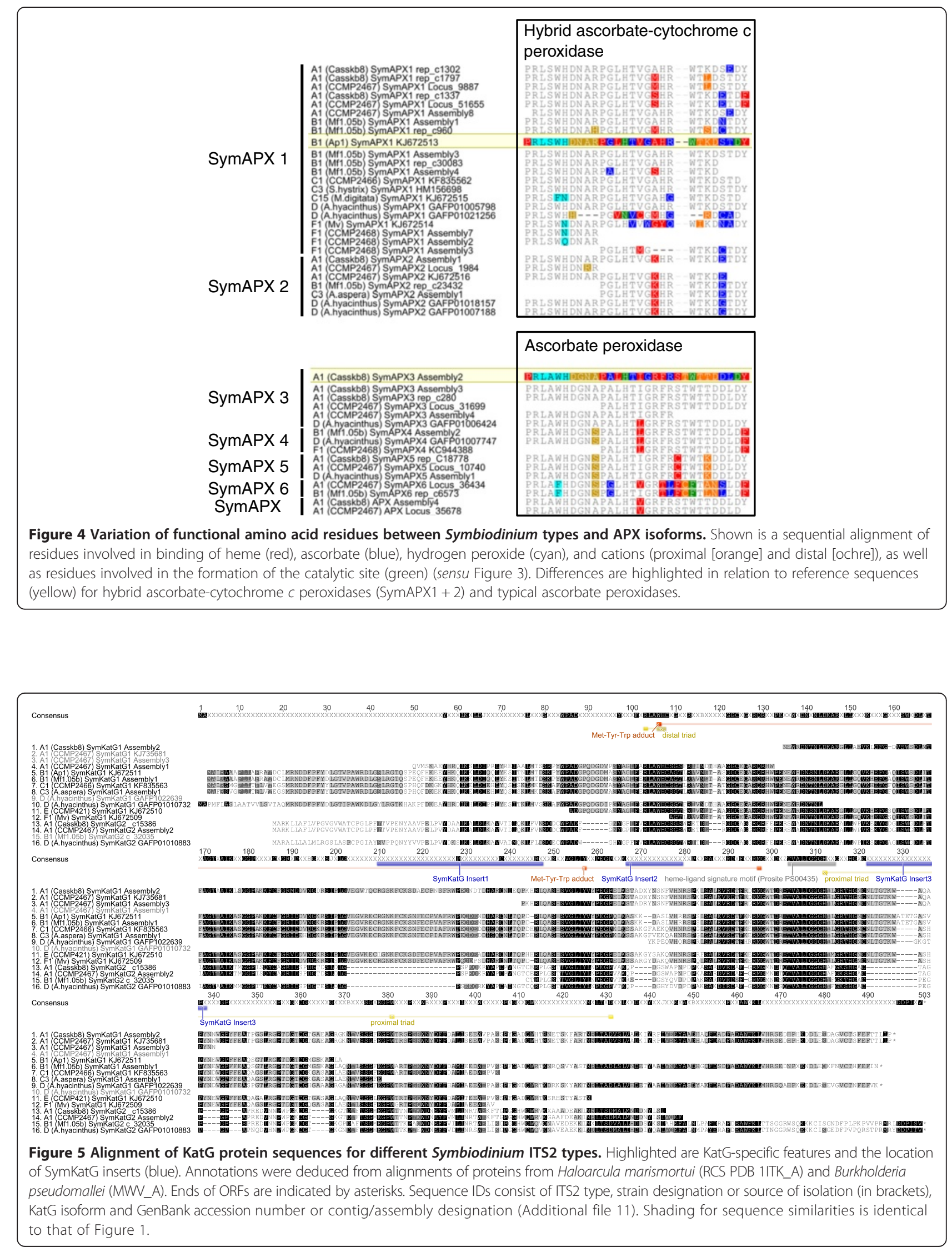
domain of the bacterial form. Residues of the distal (Trp, Arg, His) and proximal triad (His, Asp, Trp), as well as the Met-Tyr-Trp adduct are, however, all conserved. Structural modelling of the SymKatG from Symbiodinium B1 (Mf1.05b) identified the crystal structure of the bacterial catalase-peroxidase from Haloarcula marismortui (PDB:1itk) as the best structural analog (TM-score $=0.839$ ). In comparison to bacterial KatGs, SymKatGs contain up to three sequence extensions (SymKatG inserts 1-3; Figure 5, Additional file 8) at positions 210-247 (only SymKatG1; numbering according to Figure 5), 267-279 (both isoforms) and 322-338 (SymKatG1). Superimposition of the SymKatG from B1 (Mf1.05b) with Haloarcula marismortui [PDB:1itk] indicates that these inserts form large loops, primarily on the surface of the protein (Figure 6). Inserts 2 and 3 were also the main source of sequence variability between Symbiodinium types, with multiple amino acid inserts or deletions (Figure 5).

\section{Protein phylogeny}

Symbiodinium FeSOD sequences were most similar to those of the dinoflagellate Lingulodinium polyedrum. The FeSOD proteins from both of these dinoflagellates were, however, more closely related to cyanobacterial sequences (based on patristic distance) than to the general alveolate cluster; the latter also included the dinoflagellate sequence from Crypthecodinium cohnii (Figure 7). Cryptophyte and bacilliariophycean sequences formed a separate branch outside of the alveolate cluster, with another cyanobacterial sequence at its root. Overall tree

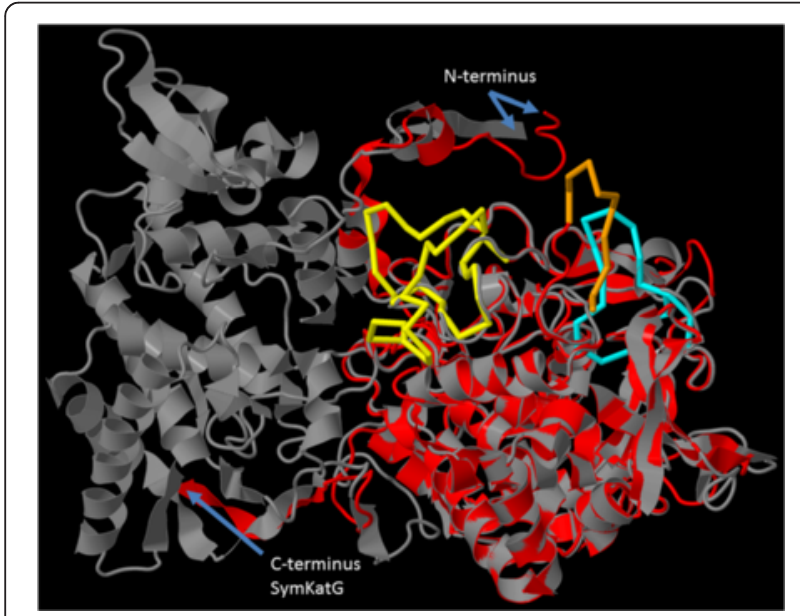

Figure 6 Superimposition of bacterial and Symbiodinium KatG. Shown are the predicted mature SymKatG1 monomers from Symbiodinium B1 (Mf1.05b, C-score $=0.09$, red) superimposed with the crystal structure monomer from Haloarcula marismortui (RCS PDB ID 1ITK_A, grey). SymKatG inserts 1 (yellow), 2 (orange) and 3 (cyan) have been highlighted in the Symbiodinium protein (cf. Figure 5, Additional file 8). robustness was low for both SOD metalloforms, with strong node support only present in lower branches.

SymMnSOD1 and 2 were grouped into a single cluster, with the pelagophyte Aureococcus anophagefferens as closest relative. Within this Symbiodinium cluster, only SymMnSOD1 from B1 were identified as a basal group, while all other sequences lacked any cladal resolution. SymMnSOD3 was most closely related to another dinoflagellate, Noctiluca scintillans, grouping it together with Ectocarpus siliculosus as well as the bacillariophycean cluster (Figure 8).

Symbiodinium APX sequences expressed a strong dichotomy relative to the rhodophyte outgroup. The tip of the lower branch (Figure 9b) separated the two clusters of SymAPX1 and SymAPX2, with the latter also containing sequences from Thalassiosira sp. (Bacillariophyceae) and Emiliania huxleyi (Prymnesiophyceae). The SymAPX1 cluster expressed some degree of cladal separation, with sequences from clades A and B usually located basally to more derived ITS2 types. SymAPX3-5, including unclassified SymAPX, formed well-separated clusters at the tip of the upper branch that comprised all dinoflagellate sequences used in the analysis. With a chloroplastic Pfiesteria piscicida sequence at its base, the dinoflagellate branch also enclosed two APX sequences from Perkinsus marinus and Ostreococcus tauri (Figure 9). Node support for cladal separation (A1 or B1 vs. D) within each SymAPX isoform was very high (100\%).

Relative to the original bacterial cluster, which also contained bacilliariophycean sequences, dinoflagellate KatGs form a strongly supported sister branch to a branch that contains chlorophyte, oomycete and phaeophycean sequences (Figure 10). While SymKatG1 and 2 form separate branches within the dinoflagellate cluster, the phylogenetic distance relative to other dinoflagellates is especially high for SymKatG1. In fact, the patristic distance between SymKatG2 (A1) and SymKatG1 (F1) is about the same as the distance between SymKatG2 (A1) and the cyanobacterium Synechococcus sp. (2.024 vs. 1.991). Cladal separation was evident for both isoforms. Resolution for SymKatG1 was limited though, indicating only a basal Symbiodinium F1 sequence, relative to a cluster of sequences from clades $\mathrm{B}, \mathrm{C}$, and $\mathrm{E}$.

\section{Protein activity and gene expression responses of enzymatic antioxidants in Symbiodinium B1 under short-term thermal stress}

Exposure to $33^{\circ} \mathrm{C}$ led to an arrest of cell population growth, relative to the control $\left(\mu=0.13 \pm 0.04 \mathrm{~d}^{-1}\right.$ at 40-50 $\mu \mathrm{mol}$ quanta $\mathrm{m}^{-2} \mathrm{~s}^{-1}$; mean $\pm \mathrm{SE}, \mathrm{N}=6$ ), and a $16 \%$ decline in $\mathrm{F}_{\mathrm{v}} / \mathrm{F}_{\mathrm{m}}$ (Table 2 ). This was, however, not accompanied by a decline in chlorophyll $a(\mathrm{Chl} a)$ content. While no significant effect of temperature on Chl $a$ or protein content was found over time, protein 


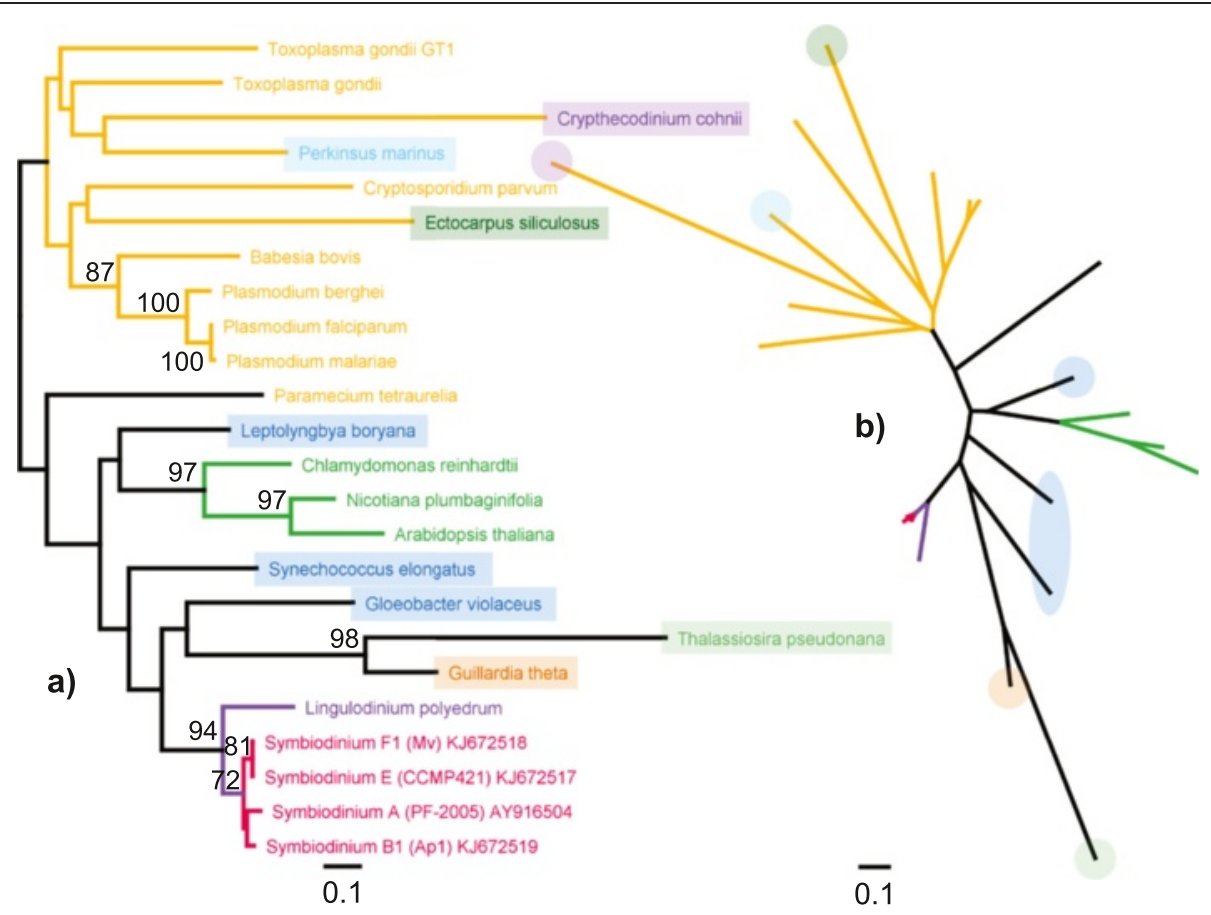

Figure 7 FeSOD protein phylogeny. Phylogeny of Symbiodinium FeSOD sequences and those of other taxa, inferred from ML analysis (WAG + I $+G$ model, 139 aa alignment length); rooted (a) and unrooted (b) trees. Scale bars indicate the number of amino acid substitutions, and bootstrap percentages $>70 \%$ are indicated on nodes. The locations of specific sequences in the unrooted tree are indicated by coloured circles. Colouring of branches refers to lineages containing Symbiodinium (red), dinoflagellates (purple), chlorophytes and higher plants (bright green), and other alveolates (orange, including the heterokont Ectocarpus siliculosus).

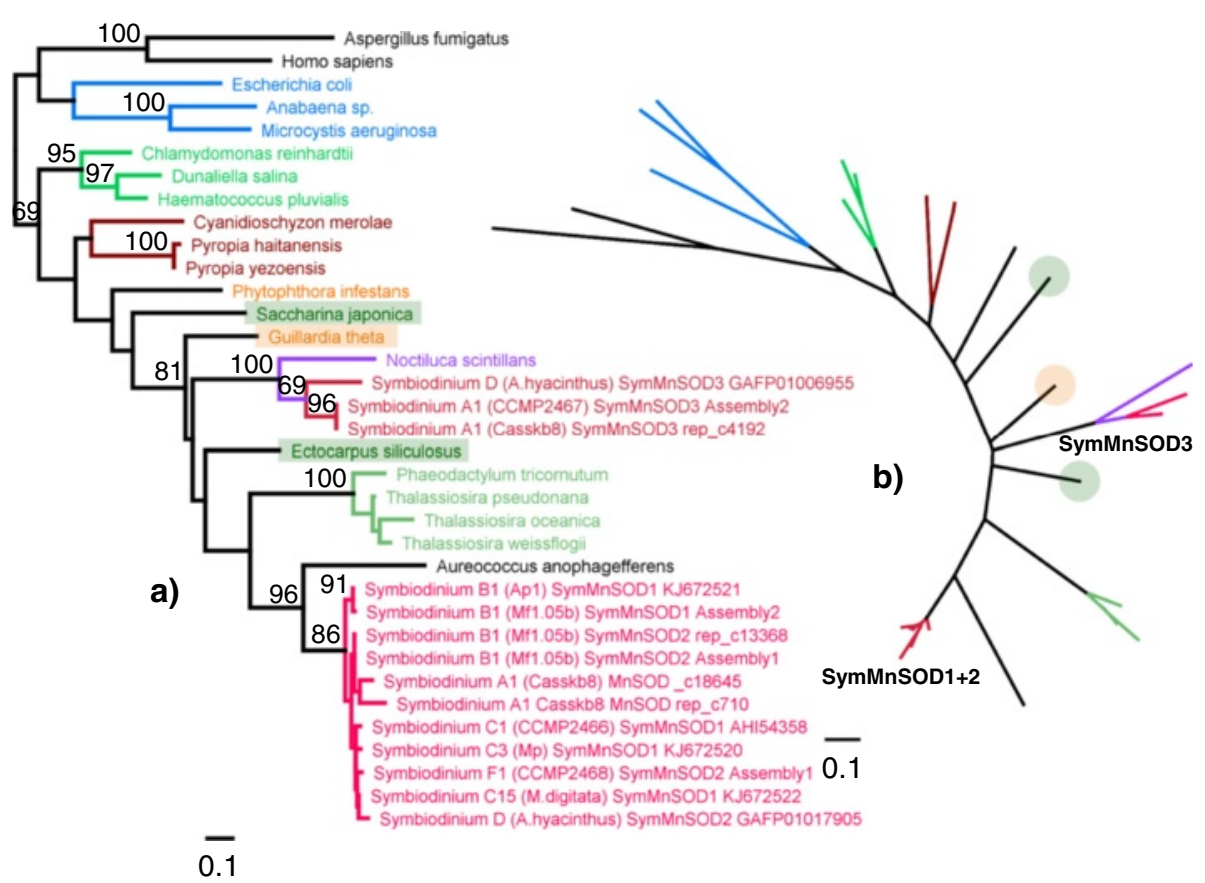

Figure 8 MnSOD protein phylogeny. Protein phylogeny as rooted (a) and unrooted (b) trees based on ML analysis (WAG + I $+\mathrm{G}$ model, 230 aa alignment length). Colouring of branches refers to lineages containing Symbiodinium (red), dinoflagellates (purple), bacillariophyceans (moss green), bacteria (blue), rhodophytes (burgundy), and chlorophytes and higher plants (bright green). 


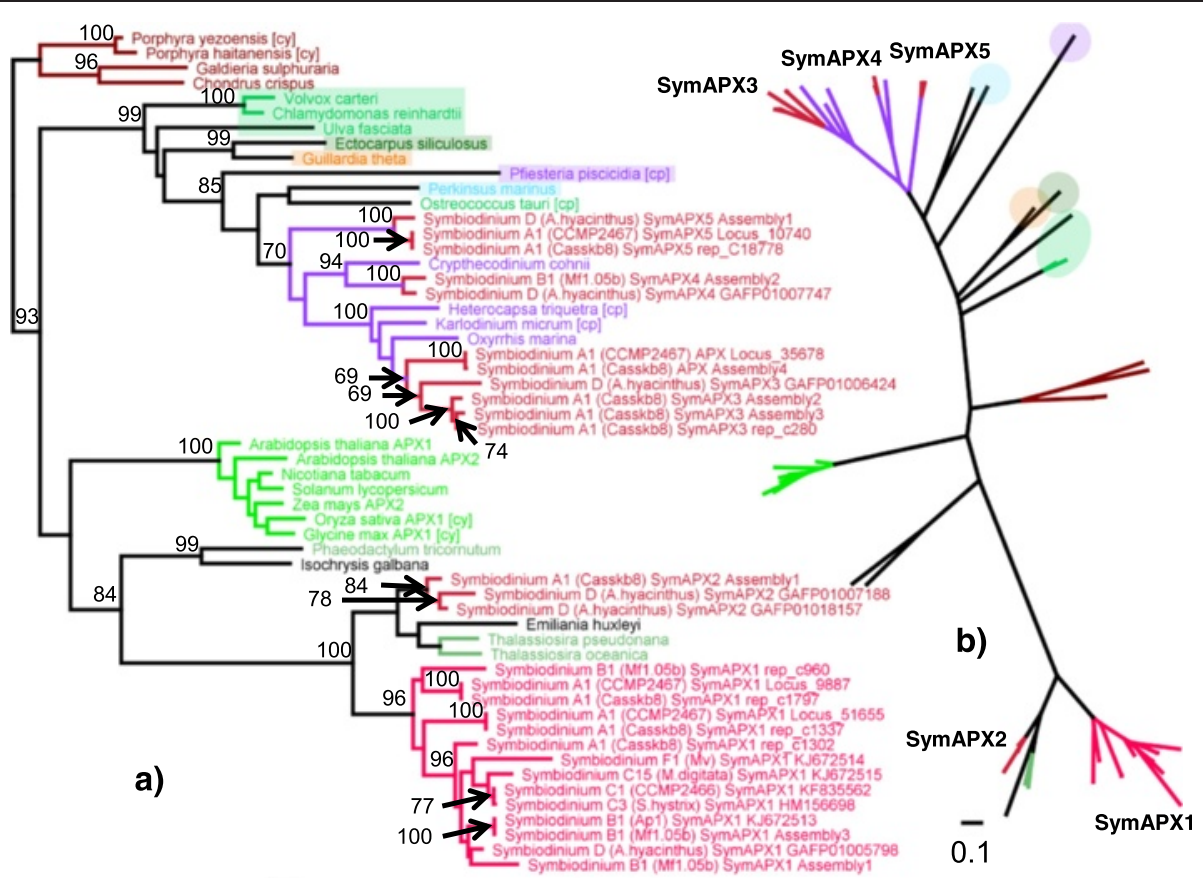

0.1

Figure 9 APX protein phylogeny. Protein phylogeny as rooted (a) and unrooted (b) trees based on ML analysis ( $L G+I+G+F$ model, 321 aa alignment length) using rhodophytes as the outgroup. Colouring of branches refers to lineages containing Symbiodinium (red), dinoflagellates (purple), bacillariophyceans (moss green), chlorophytes (green), and higher plants (bright green).

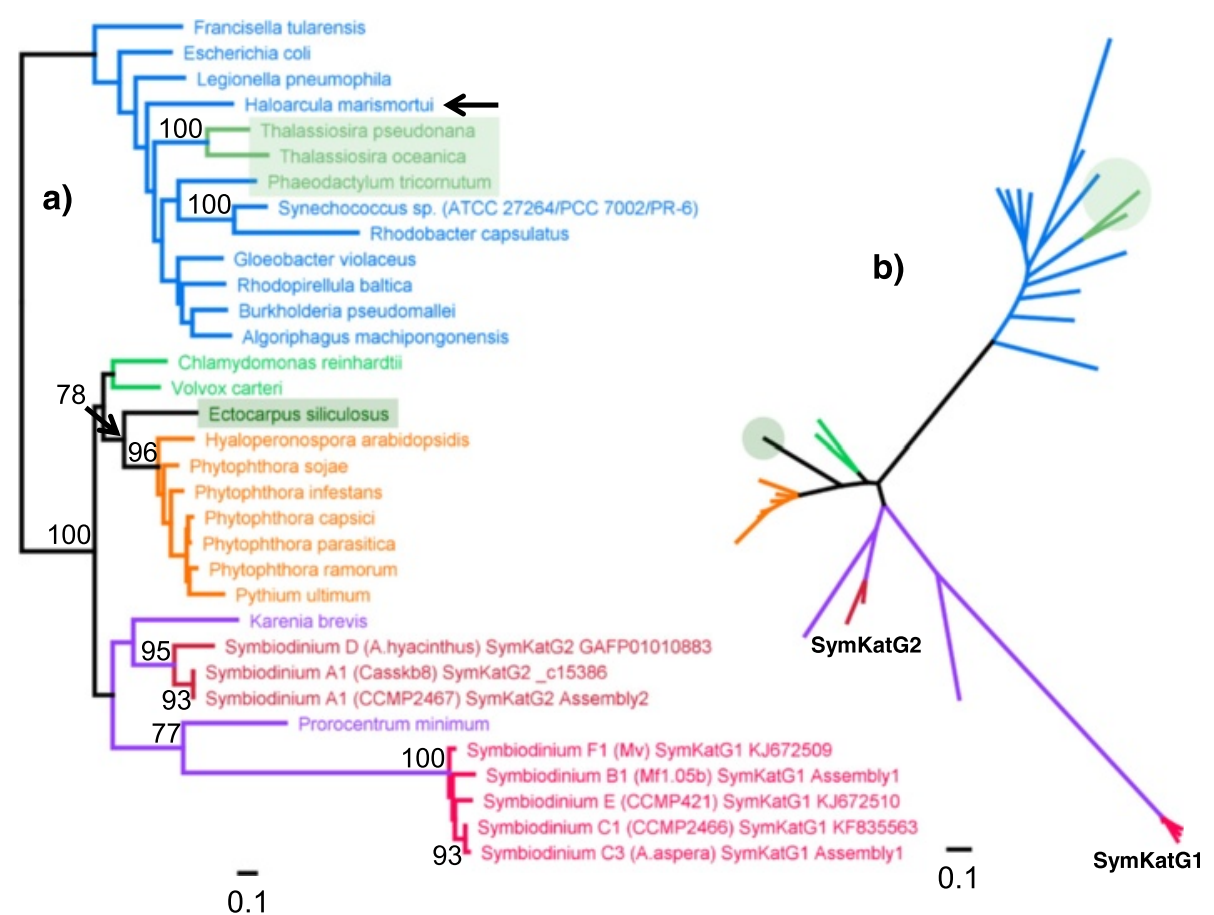

Figure 10 KatG protein phylogeny. Protein phylogeny as rooted (a) and unrooted (b) trees based on ML analysis (WAG + I + G model, 328 aa alignment length). Colouring of branches refers to lineages containing Symbiodinium (red), dinoflagellates (purple), bacteria (blue), bacillariophyceans (moss green), chlorophytes (green), and heterokont oomycetes (orange). 
Table 2 Effect of temperature on physiological variables of Symbiodinium B1

\begin{tabular}{|c|c|c|c|c|c|}
\hline Response variable & ${ }^{\circ} \mathrm{C}$ & Day 0 & Day 1 & Day 3 & $F_{\text {time } \mathrm{x} \text { temperature }}$ \\
\hline \multirow[t]{2}{*}{ Cell density } & 25 & $148920 \pm 6142$ & $161651 \pm 6553$ & $216050 \pm 10864$ & $F_{2,9}=40.3486$ \\
\hline & 33 & $151759 \pm 11152$ & $128704 \pm 6988$ & $126389 \pm 5798$ & $\mathrm{p}<0.0001^{*}$ \\
\hline \multirow[t]{2}{*}{$\mathrm{F}_{\mathrm{v}} / \mathrm{F}_{\mathrm{m}}$} & 25 & $0.51 \pm 0.01$ & $0.51 \pm 0.01$ & $0.51 \pm 0.01$ & $F_{2,9}=19.5472$ \\
\hline & 33 & $0.51 \pm 0.02$ & $0.46 \pm 0.02$ & $0.43 \pm 0.01$ & $p=0.0005^{*}$ \\
\hline Chl a & 25 & $0.85 \pm 0.05$ & $0.89 \pm 0.03$ & $0.77 \pm 0.05$ & $F_{1.263,12.63}=0.6068$ \\
\hline$\left[\mathrm{pg}\right.$ cell $\left.{ }^{-1}\right]$ & 33 & $0.90 \pm 0.03$ & $1.00 \pm 0.06$ & $0.92 \pm 0.08$ & $p=0.4875$ \\
\hline Protein & 25 & $3.82 \pm 0.31$ & $4.62 \pm 0.40$ & $4.67 \pm 0.28$ & $F_{2,9}=2.9263$ \\
\hline$\left[\mathrm{pg}\right.$ cell $\left.{ }^{-1}\right]$ & 33 & $4.74 \pm 0.46$ & $4.23 \pm 0.38$ & $5.57 \pm 0.35$ & $p=0.1049$ \\
\hline SOD & 25 & $389.6 \pm 25.7$ & $453.8 \pm 48.8$ & $541.0 \pm 33.4$ & $F_{2,9}=1.7356$ \\
\hline$\left[\mathrm{nU}\right.$ cell $\left.{ }^{-1}\right]$ & 33 & $486.3 \pm 44.4$ & $437.9 \pm 37.9$ & $594.1 \pm 34.3$ & $p=0.2304$ \\
\hline APX & 25 & $2.01 \pm 0.22$ & $2.23 \pm 0.26$ & $2.31 \pm 0.22$ & $F_{2,9}=4.2666$ \\
\hline$\left[\mathrm{nU}\right.$ cell $\left.{ }^{-1}\right]$ & 33 & $2.17 \pm 0.24$ & $2.14 \pm 0.25$ & $2.99 \pm 0.29$ & $p=0.0497^{*}$ \\
\hline KatG & 25 & $17.43 \pm 3.69$ & $15.11 \pm 2.93$ & $13.77 \pm 1.95$ & $F_{2,9}=0.7105$ \\
\hline$\left[\mathrm{nU}\right.$ cell $\left.{ }^{-1}\right]$ & 33 & $19.86 \pm 2.58$ & $20.74 \pm 3.34$ & $19.45 \pm 2.30$ & $p=0.5170$ \\
\hline
\end{tabular}

Temperature effects on viability and physiological variables in Symbiodinium B1 (in culture) over three days of exposure to $25^{\circ} \mathrm{C}$ or $33^{\circ} \mathrm{C}$. Values represent mean $\pm S E(N=6)$. Significant rmANOVA effects are indicated by asterisks.

content per cell on Day 3 tended to be higher at $33^{\circ} \mathrm{C}$ $(\mathrm{p}=0.0733)$, so we normalized enzymatic activity to cell number rather than protein content. A significant temperature effect on antioxidant enzyme activity was only found for APX, whose activity at $33^{\circ} \mathrm{C}$ was approximately 30\% higher after three days (Table 2).

Cox and Cal were identified as the best combination of HKGs, with a combined stability value of 0.006 and 0.008 at $25^{\circ} \mathrm{C}$ and $33^{\circ} \mathrm{C}$, respectively (Figure 11a). Relative expression of the remaining house-keeping genes and the target genes at $33^{\circ} \mathrm{C}$ showed no significant change over time, apart from the observation that sam and mnsod were expressed to a significantly stronger degree at $33^{\circ} \mathrm{C}$ relative to $25^{\circ} \mathrm{C}$ on Day 0 (Figure 11b). The high variability in relative expression for most of the genes on Days 0 and 1 had disappeared by Day 3, where all replicates had a similar range of expressions. These were, however, not significantly different from gene expression values in the control treatment.

\section{Discussion}

The large diversity in the dinoflagellate genus Symbiodinium has been inferred from the extensive variation in the rDNA ITS2 region [9]. While different genetic markers have been studied in the context of taxonomic resolution and phylogenetic links within the genus, individual gene phylogenies might not always be evolutionary identical (reviewed in [57]). However, to what degree this genetic diversity is reflected on the amino acid level of functionally important genes, such as antioxidant
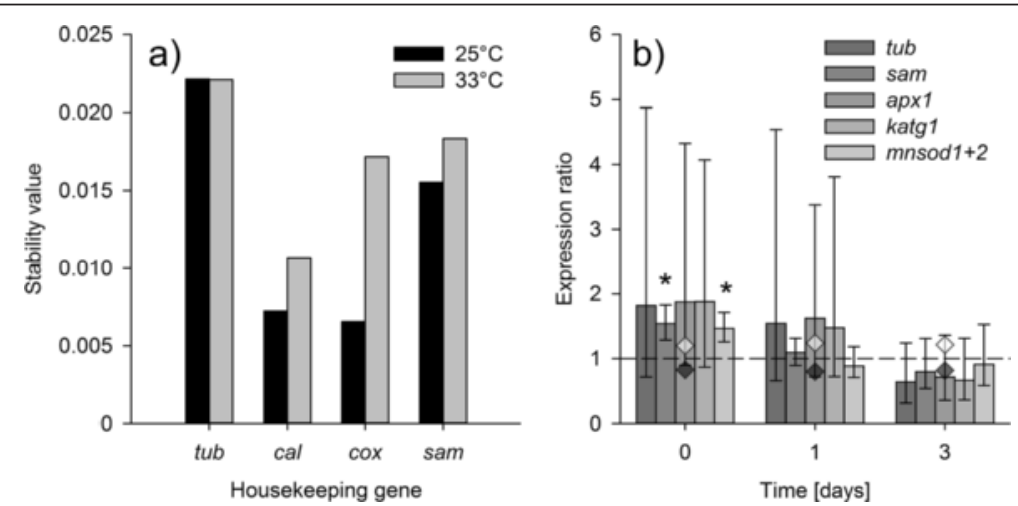

Figure 11 Symbiodinium B1 gene expression. (a) Expression stability of housekeeping genes over three days exposure to $25^{\circ} \mathrm{C}$ and $33^{\circ} \mathrm{C}$ in Symbiodinium B1 ( $\mathrm{N}=6)$. (b) Gene expression of B-tubulin (tub), S-adenosyl methionine synthetase (sam), ascorbate peroxidase (apx 1), catalase peroxidase (katg1) and manganese superoxide dismutase $(\operatorname{mnsod} 1+2)$ in $\mathrm{B} 1$ at $33^{\circ} \mathrm{C}$ relative to controls. Numbering of $\mathrm{GOI}$ designations refer to isoform numbering presented in this study (cf. Table 1). Values are means \pm SE $(N=6)$. Expression of the HKG calmodulin (white diamonds) and cytochrome $c$ oxidase subunit 1 (black diamonds) is indicated. Asterisks indicate significant up-regulation relative to the control $(p<0.05)$. 
genes, has never been investigated. This study provides, for the first time, an overview of the intrageneric diversity of the antioxidant repertoire in the genus Symbiodinium. Protein sequence characteristics and phylogenetic analyses indicated a high degree of sequence conservation at the amino acid level for SOD isoforms, but considerable variation in peroxidases. Gene expression and protein activity of MnSOD, APX and KatG were successfully measured in Symbiodinium B1 at different temperatures. Significant changes in protein activity at high temperatures were, however, limited to APX and not associated with increases in expression of the underlying gene.

\section{SOD isoforms are highly conserved between Symbiodinium types}

Structurally, all Symbiodinium MnSODs and FeSODs found here are dimeric, a characteristic that is generally found in prokaryotes rather than eukaryotes, in which MnSODs are usually tetrameric [30]. At least three MnSOD isoforms exist in Symbiodinium, agreeing with the electrophoretic detection of three to four MnSOD isoforms in Symbiodinium from two different host species [58]. The monomeric weights for the SymMnSODs $(28-33 \mathrm{kDa})$ and SymFeSOD $(21.9 \mathrm{kDa})$ correspond roughly to previously reported native (dimeric) weights of $43.5 \mathrm{kDa}$ (MnSOD) and 49.5 kDa (FeSOD) [59]. Interestingly, no FeSOD sequence was found in any of the EST libraries queried and it was not possible to readily amplify and sequence mRNA from some of the Symbiodinium types. This could be related to the fact that fesod seems to be expressed at a very low level, as high $\mathrm{C}_{\mathrm{t}}$-values and problems with non-specific amplification thwarted attempts to reliably quantify expression of this gene in Symbiodinium B1. The difficulties encountered in amplifying fesod prevent conclusions being made as to the true diversity of this form, though at least two protein isoforms were reported for Symbiodinium of the sea anemone Anemonia viridis [58]. While previous studies have established the proteomic presence of all three SOD isoforms (CuZnSOD, MnSOD, and FeSOD) in Symbiodinium $[58,59]$, the random primer approach used here detected only the manganese and iron SOD forms.

Sequence homology between Symbiodinium types was very high for both MnSOD and FeSOD. As a result, these enzymes seem to be structurally almost identical between Symbiodinium types, suggesting similar catalytic properties. This homology is also reflected in the fact that it was not possible to phylogenetically distinguish any of the seven ITS2 types within the SymMnSOD1 +2 cluster. The high degree of SOD amino acid conservation, despite the genetic radiation of the genus, shows the limitations of genetic variation in this functional gene, as mutation to critical residues involved in structural characteristics and catalytic functions might be lethal, given the pivotal role of SOD as the first line of antioxidant defence [60]. Although the dimeric nature of both SOD metalloforms indicates a bacterial origin, the protein phylogeny reflects a close relationship to cyanobacterial sequences only for FeSOD. All of the MnSOD isoforms, on the other hand, have evolved within the stramenopile cluster, consistent with a red-algal origin. Interestingly, a MnSOD from the hacrobian cryptophyte Guillardia theta (a Stramenopile-Alveolata-Rhizaria [SAR] sister lineage) was also found within this cluster.

The suggested secretory nature of 14 of the 17 SymMnSOD sequences with a complete $\mathrm{N}$-terminal domain requires further investigation with regard to the subcellular locations of these forms due to the low reliability of the prediction strength using the "plant" setting in TargetP 1.1 and the peculiar nature of transit peptides in dinoflagellates [61]. Interestingly, a variant of the plastid-targeting "FVAP"-type motif was found in almost all sequences and it should be noted that despite the predicted mitochondrial location, SymMnSOD1 and 2 fulfilled two of the three proposed cut-off criteria for transit peptides of potential plastid-targeted proteins (FVAP-type motif and less than $7.7 \%$ acidic residues [61]). With mitochondrial and chloroplast signal peptides having a number of common sequence features [62], further localisation studies beyond the bioinformatical level applied here, are required. Similarly, the absence or low reliability of a chloroplastic target signal in photosynthetic and heterotrophic dinoflagellate FeSODs from Symbiodinium of clade A (PF-2005, [GenBank:AY916504]), Crypthecodinium cohnii [GenBank: ABQ23892] and Lingulodinium polyedrum [GenBank: AF289824] emphasizes the need for such investigations, but also raises the question as to what extent plastid targeting signals differ in dinoflagellates, potentially assigning them to multiple compartments [63], or whether these FeSODs represent cytosolic forms, as suggested for heterotrophic dinoflagellates [64].

\section{Extended loops and a shortened C-terminal domain characterize Symbiodinium catalase peroxidases}

Catalase peroxidases (KatG) are bifunctional heme peroxidases which, in contrast to other peroxidases, display both catalase and peroxidase activity. These enzymes are of bacterial origin and resulted from a gene duplication event in which both protein domains remained fused while the C-terminal domain lost its catalytic activity [65]. While the exact function of this domain is unknown, it is suspected to stabilize the protein and its absence affects the spatial layout of the heme-binding residues in the catalytic domain [66,67]. The reduction or absence of the C-terminal domain has been previously observed in other dinoflagellates [68]. Evolutionarily, dinoflagellate KatGs 
belong to the minor KatG clades, which are intermediate between bifunctional KatGs and uni-functional peroxidases like APX (including hybrid APX-CcP) and cytochrome $c$ peroxidases [69]. The observed SymKatG Inserts 1 and 3 are essentially an extension of the characteristic first and second KatG loop [70], while SymKatG Insert 2 is a unique feature only shared by Prorocentrum minutum. The observed sequence variability between Symbiodinium types in these loops might be of evolutionary importance, since Loops 1 and 2 are structurally relevant for the access of hydrogen peroxide to the prosthetic heme group and thus catalytic activity $[71,72]$. Structural modifications, with alteration of amino acid residues involved in substrate and cofactor binding, can alter catalytic rates and activity of these enzymes [73], and might therefore be under selective pressure. Further research is clearly needed to bridge the gap between sequence variations and their functional consequences in different Symbiodinium types. Purifying and characterizing these enzymes biochemically will allow further investigations on the thermal stability and substrate affinity ( $\mathrm{K}_{\mathrm{m}}$-values) of these enzymes.

\section{Sequence evolution of peroxidases reflect genetic radiation of the genus Symbiodinium}

Isoforms of APX and KatG expressed a greater number of amino acid substitutions between Symbiodinium types than did SOD metalloforms, which indicates a higher rate of sequence evolution for these two phylogeneticallyrelated heme peroxidases. APX and KatG phylogenies distinguished separate Symbiodinium clades within their respective isoform clusters, even to the point of resolving subcladal diversity between $\mathrm{C} 1, \mathrm{C} 3$ (the ancestral lineage of the $\mathrm{C}$ clade), and C15. Given that clade A sequences tended to be basal to most clusters, it is conceivable that these two enzymes have co-evolved with the genetic radiation of the genus. Further data are, however, required to validate this. Sequence divergence of both heme peroxidases within the genus Symbiodinium is nevertheless large (with full length identities as low as $61 \%$ for SymAPX1 from types $\mathrm{A} 1$ and $\mathrm{B} 1$ ), and is much higher than the protein divergence seen at the genus level of higher plants (cf. Figure 9). However, while consistent features of cytosolic APXs of higher plants were found in SymAPX1 +2 (characteristic $\mathrm{His}^{334}$ [corresponding to $\mathrm{H}^{169}$ in the cytosolic APX of pea [74]] and Phe ${ }^{340}\left[\mathrm{Phe}^{175}\right.$ in the cytosolic Arabidopsis APX [75]], no typical chloroplastic isoform could be identified.

The high degree of sequence divergence between peroxidase isoforms, as well as intercladal sequence variability within each isoform, is in contrast to the high conservation in both SOD metalloforms. This lower sequence evolution in Symbiodinium SODs might be due to either lower mutation rates or a higher selective pressure on their conserved molecular function as a first line of defence. On the other hand, genetic redundancy (multiple genes with the same proteomic function potentially compensating for modification or inactivation of one of them [76]) in downstream defence lines, such as the removal of hydrogen peroxide, could provide 'evolutionary space' for alterations in peroxidase sequences to occur. This antioxidant redundancy, demonstrated in mutants of higher plants [77], has not yet been shown for Symbiodinium, partially due to the lack of available sequences for most of these genes. However, on an evolutionary scale, this redundancy might have provided the opportunity for the development of the observed sequence alterations if they become evolutionarily relevant in providing the means to more effectively detoxify ROS. Variability in downstream antioxidant responses, related to the removal of hydrogen peroxide, has already been shown to be a key difference between different Symbiodinium types under thermal stress at the protein level [36].

The presence of multiple, nuclear-encoded class I peroxidases (KatG, APX, APX-CcP) in the transcriptome of Symbiodinium, with separate modes of sequence evolution for specific isoforms, suggests that these were acquired by endosymbiosis or horizontal gene transfer (HGT). For example, APX isoforms SymAPX3-5, located within the alveolate cluster, are in stark contrast to SymAPX1-2, which were closely related to proteins from bacillariophyceae and haptophytes. Symbiodinium belongs to a cluster of dinoflagellates, called the GymnodinialesPeridiniales-Prorocentrales (GPP) complex, which contains a number of genera, whose genes were derived from plastid acquisition from bacillariophyceae and haptophytes [78], as well as through secondary and tertiary endosymbiosis (e.g., Karlodinium venificum) [79]. Our results add to other findings that Symbiodinium is no exception with regard to "foreign" genes [46,80,81]. For KatGs, a transfer of ancestral bacterial KatG genes into marine eukaryote genomes through horizontal gene transfer has been suggested; specifically, KatG acquisition from cyanobacteria or marine bacteria in diatoms has been proposed [67]. SymKatGs demonstrate, however, a more reduced $\mathrm{C}$-terminal region in comparison with diatoms. The suggested common KatG ancestry of dinoflagellates with evolutionarily distant stramenopile and chlorophyte proteins (all of them sharing the reduced C-terminal region) could suggest multiple independent gene transfer events for KatGs.

\section{Antioxidant gene expression in Symbiodinium B1}

In order to normalize antioxidant expression, a number of potential HKGs were chosen that had previously been shown to be suitable for thermal experiments with Symbiodinium C3 [82]. The Normfinder analysis for expression stability agreed with this previous study, in that tub is the least stable HKG candidate for 
studying thermal stress. However, expression of cal and cox was more stable in Symbiodinium B1 than sam, in contrast to the findings for C3. Large variation in gene expression between replicates was evident in this study and, though natural variation in gene expression has been shown for in hospite Symbiodinium populations in situ [83], there is no obvious explanation as to why this occurred under the controlled lab settings used here. Changes in gene expression in Symbiodinium under stress have consistently been found to be small [83-86]; thus, minimizing variation between replicates is crucial to resolve small, but potentially biologically meaningful changes in gene expression.

Clearly, the thermal scenario tested here arrested population growth and moderately lowered the maximum quantum yield of photosystem II in Symbiodinium B1. It was, however, insufficient for evoking a significant response in the expression and activity of most of the antioxidants monitored. Indeed, only cellular hydrogen peroxide scavenging through APX activity was significantly elevated after three days at $33^{\circ} \mathrm{C}$ in this Symbiodinium type. This lack of response within the timeframe tested, and the high degree of variation in gene expression between replicates, made it impossible to correlate changes in antioxidant gene transcripts and enzymatic activity in Symbiodinium B1. Further research about the level of regulation of these important antioxidant genes in Symbiodinium under stress is needed, as some studies highlight the importance of post-translational regulation in dinoflagellates [87-89]. The sequence data compiled here, and their successful application to measurements of antioxidant gene expression in Symbiodinium B1, provides the foundation for such studies.

\section{Conclusions}

The physiological traits that are associated with particular Symbiodinium genotypes have profound implications for their hosts, especially in obligate associations such as the coral-Symbiodinium symbiosis. The use of a consistent genetic classification of Symbiodinium types provides the foundation for any systematic investigation of the link between genetic identity and ecophysiology. However, genetic differences, as assessed by fast-evolving markers such as ITS2, should not a priori lead to the assumption of fundamentally different physiologies. Differences in "machinery" (interplay of cellular pathways to maintain cellular homeostasis) between types has been well studied, but to what extent differences in "hardware" (protein structures and catalytic properties) contribute to the particular physiology of different Symbiodinium types should also be considered. This study shows that superoxide dismutase enzymes are structurally highly similar across the investigated clades and types, whereas hydrogen peroxide-scavenging peroxidases display considerable variation in predicted amino acid residues. Intriguingly, these findings correlate to some extent with the observed similarity in SOD baseline activities between different types, but higher variability in downstream antioxidant enzymes under the same environmental settings [36]. Considering the role of oxidative stress in coral bleaching, and the connection between differential bleaching susceptibility and symbiont diversity, the presented dataset provides an important tool for further comparative studies related to the functioning and regulation of antioxidant genes in Symbiodinium.

\section{Methods}

Sequence characterization and phylogenetic analysis of antioxidant genes Symbiodinium types, RNA isolation, and CDNA generation Sequence information for the genes of interest - mnsod, fesod, apx, and katg - was generated from available monoclonal batch cultures of a range of Symbiodinium types, and the sequence results cross-checked with existing EST libraries for some of these types (Table 3). Especially in the case of fesod, amplifications were not successful for all types. EST libraries also served as a complementary source of additional isoforms, where applicable.

Total RNA from $10 \mathrm{~mL}$ of a pelleted batch culture (2000 x $g, 5 \mathrm{~min})$ from the Symbiodinium ITS2 types A1, B1, C1, C3, C15, E, and F1 (Table 3) was extracted with a bead mill $\left(50 \mathrm{~Hz}, 5 \mathrm{~min}, 4^{\circ} \mathrm{C}\right)$, using the Purelink ${ }^{\circ}$ RNA Mini Kit (Life technologies; includes DNAse treatment). cDNA was generated by reverse transcription (QuantiTect Reverse Transcription Kit, Qiagen; includes DNAse treatment) according to the manufacturer's instructions. Quantity and quality of extracted RNA was verified via spectrophotometric analysis (Nanodrop 1000, Thermo Fisher Scientific). All Symbiodinium identities were based on ITS2 sequencing and were performed as published previously [92].

\section{Primer design and amplification strategy}

Amino acid sequences for the genes of interest - mnsod, fesod, apx, and katg - from closely related taxa were obtained from GenBank [93], Uniprot [94] and Peroxibase [95], and searched against the Symbiodinium C3 EST database [46]. Matching contigs were aligned to obtain consensus sequences for the coding region of interest. Multiple primers selected at random locations across the consensus were generated for each sequence using the Primer3 [96] plug-in in Geneious ${ }^{\circ}$ 6.1.8 (Biomatters Ltd., New Zealand) and tested with cDNA derived from different Symbiodinium ITS2 types (Additional file 9). In addition, a spliced leader primer (SL-primer; $5^{\prime}$-CC GTAGCCATTTTGGCTCAAG-3'; [97]) was tested in 
Table 3 Sample and sequence information

\begin{tabular}{|c|c|c|c|c|c|c|}
\hline ITS2 type & Culture ID & Species & Isolated from & Sample origin & Data source & Reference \\
\hline$\overline{\mathrm{A} 1}$ & CCMP2467 & $\begin{array}{l}\text { Symbiodinium microadriaticum } \\
\text { subsp. microadriaticum }\end{array}$ & Stylophora pistillata & Red Sea & EST library & [90] \\
\hline $\mathrm{A} 1$ & CCMP2467 & $\begin{array}{l}\text { Symbiodinium microadriaticum } \\
\text { subsp. microadriaticum }\end{array}$ & Stylophora pistillata & Red Sea & $\begin{array}{l}\text { PCR amplification/conceptual } \\
\text { translation }\end{array}$ & this study \\
\hline $\mathrm{A} 1$ & Casskb8 & Symbiodinium microadriaticum & $\begin{array}{l}\text { Cassiopea } \\
\text { xamachana }\end{array}$ & Hawai'i & EST library & {$[45,91]$} \\
\hline B1 & Mf1.05b & Symbiodinium minutum & Orbicella faveolata & Florida Keys & EST library & {$[45]$} \\
\hline B1 & Ap1 & Symbiodinium minutum & Aiptasia pulchella & Hawai'i & $\begin{array}{l}\text { PCR amplification /conceptual } \\
\text { translation }\end{array}$ & this study \\
\hline $\mathrm{C} 1$ & CCMP2466 & Symbiodinium goreauii & $\begin{array}{l}\text { Discosoma } \\
\text { sanctithomae }\end{array}$ & Jamaica & $\begin{array}{l}\text { PCR amplification /conceptual } \\
\text { translation }\end{array}$ & this study \\
\hline C3 & N/A & N/A & Acropora aspera & Great Barrier Reef & EST library & {$[46]$} \\
\hline C3 & $\mathrm{Mp}$ & N/A & Mastigias papua & Palau & $\begin{array}{l}\text { PCR amplification /conceptual } \\
\text { translation }\end{array}$ & this study \\
\hline $\mathrm{C} 15$ & N/A & N/A & Montipora digitata & Great Barrier Reef & $\begin{array}{l}\text { PCR amplification /conceptual } \\
\text { translation }\end{array}$ & this study \\
\hline D & N/A & N/A & $\begin{array}{l}\text { Acropora } \\
\text { hyacinthus }\end{array}$ & American Samoa & EST library & [48] \\
\hline E & CCMP421 & Symbiodinium voratum & free-living & New Zealand & $\begin{array}{l}\text { PCR amplification /conceptual } \\
\text { translation }\end{array}$ & this study \\
\hline $\mathrm{F} 1$ & CCMP2468 & Symbiodinium kawagutii & Montipora capitata & Hawai'i & EST library & {$[47]$} \\
\hline $\mathrm{F} 1$ & Mv & Symbiodinium kawagutii & Montipora capitata & Hawai'i & $\begin{array}{l}\text { PCR amplification /conceptual } \\
\text { translation }\end{array}$ & this study \\
\hline
\end{tabular}

Symbiodinium types, biogeographical origin and source of antioxidant sequence data analysed in this study. The culture identification number (ID, when applicable), formal species name, source of isolation, geographic origin, and the sequencing method have been included. ITS2 = internal transcribed spacer 2; EST = expressed sequence tag; N/A = not applicable.

conjunction with working reverse primers in an attempt to amplify the $\mathrm{N}$-terminal coding region of each gene.

Primers were tested using a general PCR amplification profile, consisting of an initial denaturation of $3 \mathrm{~min}$ at $95^{\circ} \mathrm{C}$, followed by 35 cycles of $30 \mathrm{~s}$ at $95^{\circ} \mathrm{C}, 30 \mathrm{~s}$ at $54^{\circ} \mathrm{C}$ and $1 \mathrm{~min}$ at $72^{\circ} \mathrm{C}$ with a final elongation of $7 \mathrm{~min}$ at $72^{\circ} \mathrm{C}$, using MyTaq ${ }^{\mathrm{TM}}$ Red Mix (BIOLINE). PCR amplicons were visualized via gel electrophoresis (1.5-3.5\% $[\mathrm{w} / \mathrm{v}]$ agarose, using the molecular ladders Hyperladder II or $\mathrm{V}$ [BIOLINE] for estimation of amplicon size). Successful amplifications were purified using ExoSAP-IT (Global Science) and sequenced in both directions by Macrogen Inc. (Seoul, South Korea). When non-specific amplifications occurred, annealing temperatures were raised to $60^{\circ} \mathrm{C}$ to increase PCR specificity and/or bands were manually excised and purified prior to sequencing (Zymoclean ${ }^{\mathrm{TM}}$ Gel DNA Recovery Kit, according to manufacturer's recommendations).

\section{Identification, alignment and annotation of coding sequences}

Partial sequences for each gene of interest and Symbiodinium type were aligned using Clustal W [98], and the consensus sequences were searched against GenBank (Blastx) [99] for verification of identity. In addition, these sequences were searched (Blastn) against available EST libraries for
Symbiodinium types A1, B1, C3, D, and F1 in order to obtain additional sequences (Table 3).

Sequences were analysed for the presence of open reading frames (ORF) using ATGpr software [100] and translated accordingly. Amino acid sequences were analysed using Phobius [101] for the presence of signal peptides and transmembrane domains, TargetP 1.1 [102] for prediction of subcellular localisation, and GPI-SOM [103] and PredGPI [104] for the presence of a glypiation site (posttranslational attachment of glycophosphatidylinositol [GPI membrane anchor]). 3-D models, based on the mature (without $\mathrm{N}$-terminal signal) full-length amino acid sequence were developed using i-tasser [105]. Alignment of 3-D models and visual highlighting of specific features were performed in Geneious ${ }^{\circledast}$ 6.1.8.

\section{Phylogenetic analyses}

Sequences were aligned with Clustal W and trimmed to equal lengths. Appropriate phylogenetic models for protein evolution were determined with ProtTest using the Akaike Information Criterion [106]. Tree topology was determined using maximum likelihood (ML) analysis with 100 bootstraps to infer topology robustness [107,108]. Phylogenetic trees were generated using the PhyML [109] plug-in in Geneious ${ }^{\oplus} 6.1 .8$ and node supports $>70$ highlighted where appropriate. 


\section{Gene expression experiment Experimental setup}

For details on Symbiodinium cell culture and experimental methodology see Additional file 10. Briefly, batch cultures of Symbiodinium type B1 (culture ID Ap1; $\mathrm{N}=6$ per treatment), grown at $25^{\circ} \mathrm{C}$ and $40-50 \mu \mathrm{mol}$ quanta $\mathrm{m}^{-2} \mathrm{~s}^{-1}$ (LI-COR Quantum light meter LI-189 with cosine sensor, LI-COR, Inc., USA) were exposed to $33^{\circ} \mathrm{C}$ over three days after rapid heating $\left(1^{\circ} \mathrm{C} \mathrm{h}^{-1}\right)$. This Symbiodinium type was chosen, because previous experiments have indicated a high degree of thermal susceptibility under the experimental setup employed here [36]. Samples were taken on Days 0,1 and 3 by pelleting seven $50 \mathrm{~mL}$ aliquots (2000 $\mathrm{x} g, 5 \mathrm{~min})$ that were flash frozen in liquid nitrogen and stored at $-80^{\circ} \mathrm{C}$. In addition, $5-10 \mathrm{~mL}$ aliquots were taken for determination of maximum quantum yield of photosystem II $\left(\mathrm{F}_{\mathrm{v}} / \mathrm{F}_{\mathrm{m}}\right)$ via PAM fluorometry (Water-PAM chlorophyll fluorometer, Heinz Walz $\mathrm{GmbH}$, Germany) and measurement of cell density via haemocytometer counts (see Additional file 10).

\section{Viability and antioxidant activity}

Rates of asexual reproduction, $\mathrm{F}_{\mathrm{v}} / \mathrm{F}_{\mathrm{m}}$ and chlorophyll $a$ content per cell were monitored as proxies for overall cell viability (see Additional file 10 for methodological details). The molecular response was monitored via activity of SOD, APX and KatG, and all measurements were conducted according to previously published protocols (see Additional file 10). Enzyme activities were normalized per cell and expressed as specific activity $\left(\mathrm{U}_{\text {cell }}{ }^{-1}\right)$, where one unit catalyses one $\mu \mathrm{mol}$ substrate $\min ^{-1}$ cell $^{-1}$.

\section{Housekeeping genes (HKG) and genes of interest (GOI) for Symbiodinium B1}

After pooling three frozen pellets per replicate and timepoint, RNA was extracted and converted to cDNA as described above. The housekeeping genes (HKGs) ßtubulin $(t u b), \mathrm{S}$-adenosyl methionine synthetase (sam), calmodulin (cal), and cytochrome oxidase subunit 1 (cox) were chosen based on a previous study [82], with fesod, mnsod, apx and katg as genes of interest (GOI). Partial sequences for the HKGs that allowed the design of qPCR primers were obtained by either combining the SL-primer with reverse HKG primers previously used for Symbiodinium C3 [82], or amplified based on EST sequences for Symbiodinium B1 (Table 3). All qPCR primer pairs were designed with the Primer3 plug-in of Geneious $^{\oplus} 6.1 .8$, with annealing temperatures of $60^{\circ} \mathrm{C}$.

\section{Quantitative polymerase chain reaction ( $q P C R$ )}

HKG and GOI qPCR primers (Table 4) were chosen as the result of the following optimization procedure. The efficiency and specificity of different designed HKG and GOI qPCR primers were tested with a pooled cDNA sample (from all six Symbiodinium B1 replicates from $25^{\circ} \mathrm{C} /$ Day 0). Equimolar primer pair concentrations in the range of 200-1000 nM were tested for each pair and efficiency was assessed using a template dilution series (five dilution levels from 1:5-1:500). Specificity and product size were assessed via melt curve analysis and gel electrophoresis.

Real-time polymerase chain reactions (qPCRs, three per sample) were performed with $2 \mu \mathrm{L}$ of 1:50 diluted template in $20 \mu \mathrm{L}$ reaction volume, using a Power SYBR ${ }^{\oplus}$ Green Master Mix (Life Technologies). qPCRs were run on a StepOne ${ }^{T M}$ Real-Time PCR machine (Applied Biosystems, USA) and consisted of an initial incubation for $10 \mathrm{~min}$ at $95^{\circ} \mathrm{C}$, followed by 40 cycles of $15 \mathrm{~s}$ at $95^{\circ} \mathrm{C}$ and $1 \mathrm{~min}$ at $60^{\circ} \mathrm{C}$. The run was concluded with a melt curve from $60^{\circ} \mathrm{C}$ to $95^{\circ} \mathrm{C}$. All sample $\mathrm{C}_{\mathrm{t}}$-values were within the range of the template dilution series used to assess efficiency. Despite testing a number of fesod qPCR primer pairs, it was not possible to consistently assess the

Table 4 Primer properties

\begin{tabular}{|c|c|c|c|c|c|c|}
\hline Name & Gene & Forward primer $\left(5^{\prime}-3^{\prime}\right)$ & Reverse primer $\left(5^{\prime}-3^{\prime}\right)$ & $\begin{array}{l}\text { Amplicon } \\
\text { size [bp] }\end{array}$ & $\begin{array}{l}\text { Concentration } \\
\text { [nM] }\end{array}$ & Efficiency \\
\hline Calmodulin (HKG) & cal & TGATGGCGCGCAAGATGAAGG & TGCCATCGCGATCGAAAACCTTG & 78 & 750 & $98 \%$ \\
\hline $\begin{array}{l}\text { Cytochrome oxidase subunit } \\
1 \text { (HKG) }\end{array}$ & $\operatorname{cox}$ & TCTGTCTTCCTCTCACATCTCT & CCACTGCACCATTTCCAAGA & 82 & 225 & $97 \%$ \\
\hline $\begin{array}{l}\text { S-adenosyl methionine } \\
\text { synthetase (HKG) }\end{array}$ & sam & GACCAAGAACGGCATCAAGT & TGCTGCTCATGGATGCATAC & 74 & 200 & $95 \%$ \\
\hline ß-tubulin (HKG) & tub & CCAGCTITGCCATTCCCTTG & TGGTTCCACCACTGTGTCAG & 148 & 750 & $94 \%$ \\
\hline $\begin{array}{l}\text { Hybrid ascorbate-cytochrome } \\
\text { c peroxidase (GOI) }\end{array}$ & $a p \times 1$ & CAATGTGGCACTCATGCTGG & TAAGCTTCTCAAGGTCCGCC & 107 & 500 & $102 \%$ \\
\hline Catalase peroxidase (GOI) & katg1 & TCTTCTTGGCCAAGTGAAGC & TTTGATGGCAGTGGTTCCTG & 85 & 500 & $96 \%$ \\
\hline $\begin{array}{l}\text { Manganese superoxide } \\
\text { dismutase (GOl) }\end{array}$ & $\operatorname{mnsod} 1+2$ & CAACCCCAAACCAGGACAAT & CACATCCCACCAAGCTTTGA & 146 & 1000 & $96 \%$ \\
\hline
\end{tabular}

Primer sequences, amplicon size, equimolar primer concentrations and efficiency for housekeeping genes (HKGs) and antioxidant genes of interest (GOI) used for quantitative real-time PCR-based (SYBR ${ }^{\oplus}$ Green) gene expression in Symbiodinium type B1. The isoform designations for the antioxidant genes are based on results presented in this study. 
expression of this gene due to multiple peaks in the melting curve or low efficiencies.

\section{Statistical analysis}

Physiological variables were analysed for temperature and time effects using repeated measures analysis of variance (rmANOVA). Cell densities were log transformed and $\mathrm{F}_{\mathrm{v}} / \mathrm{F}_{\mathrm{m}}$ values were arcsine square root transformed. Datasets were tested for sphericity with Mauchly's sphericity test. The results of Pillai's trace test or epsilonadjusted univariate F-tests (Greenhouse-Geisser; G-G) at a confidence level of 0.05 are reported. Reported post hoc contrasts were adjusted for multiple comparisons, using the Bonferroni correction. Data were analysed using JMP 10.0.0 (SAS Institute Inc., USA).

Stable HKGs were identified by comparing HKG expression at $25^{\circ} \mathrm{C}$ and $33^{\circ} \mathrm{C}$ over time using the software Normfinder [110]. Relative gene expression was calculated from $\mathrm{C}_{\mathrm{t}}$-values, using REST 2009 with 10000 iterations [111].

\section{Availability of supporting data}

Primary references for used Symbiodinium EST libraries are given in Table 3. The complete list of used contigs (contig designations are library-specific) and derived assemblies, as well as NCBI accession numbers (where applicable) are given in Additional file 11. A list of used primers to amplify antioxidant cDNA fragments is provided in Additional file 9. All explicit amino acid sequences are provided in Figures 1, 3 and 5 and available in txt format in Additional files 12, 13, and 14.

\section{Additional files}

Additional file 1: SOD pairwise amino acid identities. Pairwise amino acid sequence identities of MnSOD (\#1-21) and FeSOD (\#22-25) sequences from different Symbiodinium ITS2 types based on the alignment in Figure 1. Pairwise identities between full length sequences (green) and pairwise identities within clade C (yellow) have been highlighted.

Additional file 2: MnSOD signal peptide location. Location of signal peptide (magenta) and ancient transit peptide motif (red) in the N-terminal region of MnSOD sequences from different Symbiodinium ITS2 types. Sequence IDs consist of ITS2 type, strain designation or source of isolation (in brackets), MnSOD isoform and NCBI accession number or contig/assembly designation (Additional file 11).

Additional file 3: Classification of Symbiodinium peroxidases. "Peroxiscan" classification and BLAST (blastp) results for different Symbiodinium peroxidase isoforms (http://peroxibase.toulouse.inra.fr).

Additional file 4: APX signal peptide location. Location of signal peptide (magenta) and transmembrane domains (red) in the N-terminal region of APX sequences from different Symbiodinium ITS2 types. Sequence IDs consist of ITS2 type, strain designation or source of isolation (in brackets), APX isoform and NCBI accession number or contig/assembly designation (Additional file 11).

Additional file 5: APX pairwise amino acid identities. Pairwise amino acid sequence identities of APX sequences from different Symbiodinium ITS2 types based on the alignment in Figure 3. Pairwise identities between full length sequences (green) and pairwise identities within clade C (yellow) have been highlighted.

Additional file 6: KatG signal peptide location. Location of signal peptide (magenta) and transmembrane domains (red) in the N-terminal region of KatG sequences from different Symbiodinium ITS2 types. Sequence IDs consist of ITS2 type, strain designation or source of isolation (in brackets), APX isoform and NCBI accession number or contig/assembly designation (Additional file 11).

Additional file 7: KatG pairwise amino acid identities. Pairwise amino acid sequence identities of KatG sequences from different Symbiodinium ITS2 types based on the alignment in Figure 5. Pairwise identities between full length sequences (green) and pairwise identities within clade $C$ (yellow) have been highlighted.

Additional file 8: Location of SymKatG inserts. Schematization of KatG protein alignment used for the phylogenetic analysis (Figure 10). Size and location of SymKatG inserts relative to other organisms are indicated in blue. Shading indicates site-specific similarity over all sequences as $100 \%$ (black), $80-100 \%$ (dark grey), $60-80 \%$ (light grey), and less than $60 \%$ (white), based on the Blosum62 score matrix with a threshold of 1. Symbiodinium sequence IDs consist of ITS2 type, strain designation or source of isolation (in brackets), KatG isoform and NCBI accession number or contig/assembly designation (Additional file 11).

Additional file 9: Primer list. Primer sequences of successful fragment amplifications, used for assemblies of antioxidant genes of interest. Sequence IDs contain ITS2 type, strain designation or source of isolation (in brackets) and GenBank accession number.

Additional file 10: Supplementary Methods. Detailed information on experimental setup, PAM fluorometry and growth measurements, sample processing and enzyme measurement for gene expression experiment.

Additional file 11: Sequence details. List of biogeographic origin and sequence IDs and accession numbers of used contigs for all antioxidant sequences presented in this study. New sequences generated in this study are highlighted $\left(^{*}\right)$.

Additional file 12: SOD alignment. Symbiodinium superoxide dimutase $(\mathrm{Mn} / \mathrm{Fe})$ amino acid alignment (Figure 1) in txt format.

Additional file 13: APX alignment. Symbiodinium ascorbate peroxidase amino acid alignment (Figure 3) in txt format.

Additional file 14: KatG alignment. Symbiodinium catalase peroxidase amino acid alignment (Figure 5) in txt format.

\section{Abbreviations}

APX: Ascorbate peroxidase; APX-CcP: Hybrid ascorbate-cytochrome $c$ peroxidases; Cal: Calmodulin; Chl a: Chlorophyll $a$; Cox: Cytochrome oxidase subunit 1; EST: Expressed sequence tags; FeSOD: Iron superoxide dismutase; $F_{v} / F_{m}$ : Maximum quantum yield of photosystem II; G-G: Greenhouse-Geisser; GOI: Gene of interest; GPI: Glycosylphosphatidylinositol; HKG: House-keeping gene; ITS2: Internal transcribed spacer 2; KatG: Catalase peroxidase; MnSOD: Manganese superoxide dismutase; mRNA: Messenger ribonucleic acid; ORF: Open reading frame; OTU: Operational taxonomic unit; PDB: Protein data bank; qPCR: Real-time polymerase chain reaction; rDNA: Ribosomal deoxyribonucleic acid; rmANOVA: Repeated measures analysis of variance; ROS: Reactive oxygen species; SAM: S-adenosyl methionine synthetase; SAR: Stramenopile-Alveolata-Rhizaria; SOD: Superoxide dismutase; Tub: B-tubulin.

\section{Competing interests}

The authors declare that they have no competing interests.

\section{Authors' contributions}

TK, PLF, and SKD designed all experimental work. TK, SB, SP, and PLF carried out lab work for sequence characterization, including exploratory PCRs. The gene expression experiment was conducted by TK, SB, and PLF (enzymatic assays TK, SB; gene expression TK, PLF). Data analysis was conducted by TK and SP. All authors wrote the manuscript. All authors read and approved the final manuscript. 


\section{Acknowledgements}

This work was funded by a Royal Society of New Zealand Marsden Fund grant (contract number VUW0902) to SKD, PLF, SD, OH-G and WL and supported by a Marsden-funded PhD scholarship to TK. Thanks are given to Dr. Anderson Mayfield for critical commentary on the manuscript and Prof. Christian Voolstra for access to the Symbiodinium A1 CCMP2467 EST library prior to publication.

\section{Author details}

'School of Biological Sciences, Victoria University of Wellington, Wellington 6140, New Zealand. 'Laboratory for Biological Geochemistry, ENAC, École polytechnique fédérale de Lausanne (EPFL), Lausanne 1015, Switzerland. ${ }^{3}$ School of Civil Engineering, University of Queensland, St Lucia QLD 4072, Australia. ${ }^{4}$ School of Biological Sciences \& ARC Centre of Excellence for Coral Reef Studies, University of Queensland, Brisbane QLD, 4072, Australia. ${ }^{5} \mathrm{Global}$ Change Institute, University of Queensland, Brisbane QLD 4072, Australia. ${ }^{6}$ Comparative Genomics Centre, School of Pharmacy and Molecular Sciences \& ARC Centre of Excellence for Coral Reef Studies, James Cook University, Townsville QLD 4811, Australia.

\section{Received: 6 October 2014 Accepted: 24 February 2015}

\section{Published online: 18 March 2015}

\section{References}

1. Stat M, Carter D, Hoegh-Guldberg O. The evolutionary history of Symbiodinium and scleractinian hosts - Symbiosis, diversity, and the effect of climate change. Perspect Plant Ecol Evol Syst. 2006;8:26-43.

2. Muscatine L, Porter JW. Reef corals: mutualistic symbioses adapted to nutrient-poor environments. Bioscience. 1977;27(7):454-60.

3. McLaughlin JJA, Zahl PA. Axenic zooxanthellae from various invertebrate hosts. Ann N Y Acad Sci. 1959;77:55-72.

4. Freudenthal HD. Symbiodinium gen. nov. and Symbiodinium microadriaticum sp. nov., a Zooxanthella : Taxonomy, life cycle, and morphology. J Protozool. $1962 ; 9(1): 45-52$.

5. Kawaguti S. On the physiology of reef corals. VII. Zooxanthella of the reef corals is Gymnodinium sp., Dinoflagellata; its culture in vitro. Palao Trop Biol Stn Stud. 1944;2:675-9.

6. Schoenberg DA, Trench RK. Genetic variation in Symbiodinium (=Gymnodinium) microadriaticum Freudenthal, and specificity in its symbiosis with marine invertebrates. I. Isoenzyme and soluble protein patterns of axenic cultures of Symbiodinium microadriaticum. Proc R Soc B. 1980;207(1169):405-27.

7. Schoenberg DA, Trench RK. Genetic variation in Symbiodinium (=Gymnodinium) microadriaticum Freudenthal, and specificity in its symbiosis with marine invertebrates. II. Morphological variation in Symbiodinium microadriaticum. Proc R Soc B. 1980;207(1169):429-44.

8. Rowan $R$, Powers DA. Molecular genetic identification of symbiotic dinoflagellates (zooxanthellae). Mar Ecol Prog Ser. 1991;71:65-73.

9. LaJeunesse TC. Investigating the biodiversity, ecology and phylogeny of endosymbiotic dinoflagellates in the genus Symbiodinium using the ITS region: In search of a "species" level marker. J Phycol. 2001;37:866-80.

10. Rowan R, Powers DA. Ribosomal RNA sequences and the diversity of symbiotic dinoflagellates (zooxanthellae). Proc Natl Acad Sci U S A. 1992:89(8):3639-43.

11. Pochon X, Gates RD. A new Symbiodinium clade (Dinophyceae) from soritid foraminifera in Hawai'i. Mol Phylogenet Evol. 2010;56:492-7.

12. Coffroth MA, Santos SR. Genetic diversity of symbiotic dinoflagellates in the genus Symbiodinium. Protist. 2005;156:19-34.

13. Takabayashi M, Santos SR, Cook CB. Mitochondrial DNA phylogeny of the symbiotic dinoflagellates (Symbiodinium, Dinophyta). J Phycol. 2004:40:160-4.

14. Santos SR, Taylor DJ, Kinzie III RA, Hidaka M, Sakai K, Coffroth MA. Molecular phylogeny of symbiotic dinoflagellates inferred from partial chloroplast large subunit (23S)-rDNA sequences. Mol Phylogenet Evol. 2002;23:97-111.

15. Takishita K, Ishikura M, Koike MT. Comparison of phylogenies based on nuclear-encoded SSU rDNA and plastid-encoded psbA in the symbiotic dinoflagellate genus Symbiodinium. Phycologia. 2003;42(3):285-91.

16. Sampayo EM, Dove S, LaJeunesse TC. Cohesive molecular genetic data delineate species diversity in the dinoflagellate genus Symbiodinium. Mol Ecol. 2009;18:500-19.
17. Stern RF, Horak A, Andrew RL, Coffroth M-A, Andersen RA, Küpper FC, et al Environmental barcoding reveals massive dinoflagellate diversity in marine environments. PLoS One. 2010;5(11):e13991.

18. Arif C, Daniels C, Bayer T, Banguera-Hinestroza E, Barbrook A, Howe CJ, et al. Assessing Symbiodinium diversity in scleractinian corals via next-generation sequencing-based genotyping of the ITS2 rDNA region. Mol Ecol. 2014;23(17):4418-33.

19. Thornhill DJ, Lewis AM, Wham DC, LaJeunesse TC. Host-specialist lineages dominate the adaptive radiation of reef coral endosymbionts. Evolution. 2014;68(2):352-67.

20. LaJeunesse TC. "Species" radiations of symbiotic dinoflagellates in the Atlantic and Indo-Pacific since the Miocene-Pliocene transition. Mol Biol Evol. 2005;22(3):570-81.

21. Glynn PW. Coral reef bleaching: facts, hypotheses and implications. Glob Change Biol. 1996;2:495-509.

22. Hoegh-Guldberg O. Climate change, coral bleaching and the future of the world's coral reefs. Mar Freshw Res. 1999;50:839-66.

23. Hughes TP, Baird AH, Bellwood DR, Card M, Connolly SR, Folke C, et al. Climate change, human impacts, and the resilience of coral reefs. Science. 2003;301(5635):929-33.

24. Rowan R. Coral bleaching: Thermal adaptation in reef coral symbionts. Nature. 2004;430(7001):742.

25. Fisher PL, Malme MK, Dove S. The effect of temperature stress on coralSymbiodinium associations containing distinct symbiont types. Coral Reefs. 2012;31(2):473-85.

26. Berkelmans R, van Oppen MJH. The role of zooxanthellae in the thermal tolerance of corals: a 'nugget of hope' for coral reefs in an era of climate change. Proc R Soc B. 2006;273:2305-12.

27. Stat M, Morris E, Gates RD. Functional diversity in coral-dinoflagellate symbiosis. Proc Natl Acad Sci U S A. 2008;105(27):9256-61.

28. Lesser MP. Coral bleaching: causes and mechanisms. In: Dubinksy Z, Stambler N, editors. Coral Reefs: An Ecosystem in Transition. Heidelberg, Germany: Springer; 2011. p. 405-19.

29. Weis VM. Cellular mechanisms of cnidarian bleaching: stress causes the collapse of symbiosis. J Exp Biol. 2008;211:3059-66.

30. Halliwell B, Gutteridge JMC, editors. Free radicals in biology and medicine. 4th ed. Oxford, UK: Oxford University Press; 2007.

31. Alscher RG, Erturk N, Heath LS. Role of superoxide dismutases (SODs) in controlling oxidative stress in plants. J Exp Bot. 2002;53(372):1331-41.

32. Foyer $\mathrm{CH}$, Noctor $\mathrm{G}$. Ascorbate and glutathione: the heart of the redox hub. Plant Physiol. 2011;155(1):2-18.

33. Lesser MP. Elevated temperatures and ultraviolet radiation cause oxidative stress and inhibit photosynthesis in symbiotic dinoflagellates. Limnol Oceanogr. 1996:41(2):271-83.

34. McGinty ES, Pieczonka J, Mydlarz LD. Variations in reactive oxygen release and antioxidant activity in multiple Symbiodinium types in response to elevated temperature. Microb Ecol. 2012;64(4):1000-7.

35. Lesser MP. Oxidative stress causes coral bleaching during exposure to elevated temperatures. Coral Reefs. 1997;16(3):187-92.

36. Krueger T, Becker S, Pontasch S, Dove S, Hoegh Guldberg O, Leggat W, et al. Antioxidant plasticity and thermal sensitivity in four types of Symbiodinium sp. J Phycol. 2014;50(6):1035-47.

37. Yakovleva IM, Baird AH, Yamamoto HH, Bhagooli R, Nonaka M, Hidaka M Algal symbionts increase oxidative damage and death in coral larvae at high temperatures. Mar Ecol Prog Ser. 2009;378:105-12.

38. Noel RJ, Matta JL. Partial cloning of MnSOD and FeSOD genes from the dinoflagellate Symbiodinium microadriaticum. Free Radical Biol Med. 1999;27(Supplement 1):S22.

39. Kortschak RD, Samuel G, Saint R, Miller DJ. EST analysis of the cnidarian Acropora millepora reveals extensive gene loss and rapid sequence divergence in the model invertebrates. Curr Biol. 2003;13(24):2190-5.

40. Forêt S, Kassahn KS, Grasso L, Hayward D, Iguchi A, Ball E, et al. Genomic and microarray approaches to coral reef conservation biology. Coral Reefs. 2007;26(3):475-86

41. Miller DJ, Hemmrich G, Ball EE, Hayward DC, Khalturin K, Funayama N, et al. The innate immune repertoire in Cnidaria-ancestral complexity and stochastic gene loss. Genome Biol. 2007;8(4):R59.

42. DeSalvo MK, Voolstra CR, Sunagawa S, Schwarz JA, Stillman JH, Coffroth MA, et al. Differential gene expression during thermal stress and bleaching in the Caribbean coral Montastraea faveolata. Mol Ecol. 2008;17(17):3952-71. 
43. Shinzato C, Shoguchi E, Kawashima T, Hamada M, Hisata K, Tanaka M, et al. Using the Acropora digitifera genome to understand coral responses to environmental change. Nature. 2011;476(7360):320-3.

44. Schwarz JA, Brokstein PB, Voolstra C, Terry AY, Miller DJ, Szmant AM, et al. Coral life history and symbiosis: functional genomic resources for two reef building Caribbean corals, Acropora palmata and Montastraea faveolata. BMC Genomics. 2008;9(1):97.

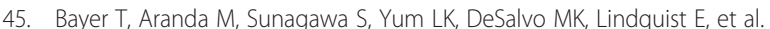
Symbiodinium transcriptomes: Genome insights into the dinoflagellate symbionts of reef-building corals. PLoS One. 2012;7(4):e35269.

46. Leggat W, Hoegh-Guldberg O, Dove S, Yellowlees D. Analysis of an EST library from the dinoflagellate (Symbiodinium sp.) symbiont of reef building corals. J Phycol. 2007;43(5):1010-21.

47. Zhang H, Zhuang Y, Gill J, Lin S. Proof that dinoflagellate spliced leader (DinoSL) is a useful hook for fishing dinoflagellate transcripts from mixed microbial samples: Symbiodinium kawagutii as a case study. Protist. 2013;164(4):510-27.

48. Ladner JT, Barshis DJ, Palumbi SR. Protein evolution in two co-occurring types of Symbiodinium: an exploration into the genetic basis of thermal tolerance in Symbiodinium clade D. BMC Evol Biol. 2012;12(1):217.

49. Rodriguez-Lanetty M, Harii S, Hoegh-Guldberg O. Early molecular responses of coral larvae to hyperthermal stress. Mol Ecol. 2009;18:5101-14.

50. Polato NR, Voolstra CR, Schnetzer J, DeSalvo MK, Randall CJ, Szmant AM, et al. Location-specific responses to thermal stress in larvae of the reef-building coral Montastraea faveolata. PLoS One. 2010;5(6):e11221.

51. Császár N, Seneca F, van Oppen M. Variation in antioxidant gene expression in the scleractinian coral Acropora millepora under laboratory thermal stress. Mar Ecol Prog Ser. 2009;392(93):102.

52. Edge SE, Morgan MB, Snell TW. Temporal analysis of gene expression in a field population of the scleractinian coral Montastraea faveolata. J Exp Mar Biol Ecol. 2008;355(2):114-24.

53. Putnam H, Mayfield A, Fan T, Chen C, Gates R. The physiological and molecular responses of larvae from the reef-building coral Pocillopora damicornis exposed to near-future increases in temperature and $\mathrm{pCO}_{2}$. Mar Biol. 2012;160:2157-73.

54. Mayfield AB, Wang L-H, Tang P-C, Fan T-Y, Hsiao Y-Y, Tsai C-L, et al. Assessing the impacts of experimentally elevated temperature on the biological composition and molecular chaperone gene expression of a reef coral. PLoS One. 2011;6(10):e26529.

55. Wintjens R, Gilis D, Rooman M. Mn/Fe superoxide dismutase interaction fingerprints and prediction of oligomerization and metal cofactor from sequence. Proteins. 2008;70(4):1564-77.

56. Pitsch NT, Witsch B, Baier M. Comparison of the chloroplast peroxidase system in the chlorophyte Chlamydomonas reinhardtii, the bryophyte Physcomitrella patens, the lycophyte Selaginella moellendorffii and the seed plant Arabidopsis thaliana. BMC Plant Biol. 2010;10(1):133.

57. Pochon X, Putnam HM, Gates RD. Multi-gene analysis of the symbiotic and free-living dinoflagellate genus Symbiodinium. PeerJ. 2014;2:e394.

58. Richier S, Merle P-L, Furla P, Pigozzi D, Sola F, Allemand D. Characterization of superoxide dismutases in anoxia- and hyperoxia-tolerant symbiotic cnidarians. Biochim Biophys Acta. 2003;1621:84-91.

59. Matta JL, Govind NS, Trench RK. Polyclonal antibodies against iron-superoxide dismutase from Escherichia coli B cross-react with superoxide dismutase from Symbiodinium microadriaticum (Dinophyceae). J Phycol. 1992;28:343-6.

60. Cooper GM, Brown CD. Qualifying the relationship between sequence conservation and molecular function. Genome Res. 2008;18(2):201-5.

61. Patron NJ, Waller RF, Archibald JM, Keeling PJ. Complex protein targeting to dinoflagellate plastids. J Mol Biol. 2005;348(4):1015-24.

62. Zhang X-P, Glaser E. Interaction of plant mitochondrial and chloroplast signal peptides with the Hsp70 molecular chaperone. Trends Plant Sci. 2002;7(1):14-21.

63. Bodył A, Mackiewicz P. Analysis of the targeting sequences of an ironcontaining superoxide dismutase (SOD) of the dinoflagellate Lingulodinium polyedrum suggests function in multiple cellular compartments. Arch Microbiol. 2007;187(4):281-96.

64. Dufernez F, Derelle E, Noël C, Sanciu G, Mantini C, Dive D, et al. Molecular characterization of iron-containing auperoxide dismutases in the heterotrophic dinoflagellate Crypthecodinium cohnii. Protist. 2008;159(2):223-38.

65. Welinder KG. Bacterial catalase-peroxidases are gene duplicated members of the plant peroxidase superfamily. Biochim Biophys Acta. 1991;1080(3):215-20.
66. Baker RD, Cook CO, Goodwin DC. Properties of catalase-peroxidase lacking its C-terminal domain. Biochem Biophys Res Commun. 2004;320(3):833-9.

67. Zámocký M, Furtmüller PG, Obinger C. Evolution of structure and function of Class I peroxidases. Arch Biochem Biophys. 2010;500(1):45-57.

68. Guo R, Ki JS. Characterization of a novel catalase-peroxidase (KatG) gene from the dinoflagellate Prorocentrum minimum. J Phycol. 2013;49:1011-6.

69. Zámocký M, Gasselhuber B, Furtmüller PG, Obinger C. Turning points in the evolution of peroxidase-catalase superfamily: molecular phylogeny of hybrid heme peroxidases. Cell Mol Life Sci. 2014;71:1-16.

70. Zámocký M, Regelsberger G, Jakopitsch C, Obinger C. The molecular peculiarities of catalase-peroxidases. FEBS Lett. 2001;492(3):177-82.

71. Li Y, Goodwin DC. Vital roles of an interhelical insertion in catalase-peroxidase bifunctionality. Biochem Biophys Res Commun. 2004;318(4):970-6.

72. Smulevich $\mathrm{G}$, Jakopitsch $\mathrm{C}$, Droghetti $\mathrm{E}$, Obinger $\mathrm{C}$. Probing the structure and bifunctionality of catalase-peroxidase (KatG). J Inorg Biochem. 2006;100(4):568-85.

73. Gutteridge A, Thornton JM. Understanding nature's catalytic toolkit. Trends Biochem Sci. 2005;30(11):622-9.

74. Wada K, Tada T, Nakamura Y, Ishikawa T, Yabuta Y, Yoshimura K, et al. Crystal structure of chloroplastic ascorbate peroxidase from tobacco plants and structural insights into its instability. J Biochem. 2003;134(2):239-44.

75. Jespersen H, Kjaersgård IVH, Østergaard L, Welinder KG. From sequence analysis of three novel ascorbate peroxidases from Arabidopsis thaliana to structure, function and evolution of seven types of ascorbate peroxidase. Biochem J. 1997:326:305-10.

76. Nowak MA, Boerlijst MC, Cooke J, Smith JM. Evolution of genetic redundancy. Nature. 1997;388(6638):167-71.

77. Mittler R, Vanderauwera S, Gollery M, Van Breusegem F. Reactive oxygen gene network of plants. Trends Plant Sci. 2004;9(10):490-8.

78. Wisecaver JH, Hackett JD. Dinoflagellate genome evolution. Annu Rev Microbiol. 2011;65:369-87.

79. Patron NJ, Waller RF, Keeling PJ. A tertiary plastid uses genes from two endosymbionts. J Mol Biol. 2006;357(5):1373-82.

80. Takishita K, Ishida K-I, Maruyama T. An enigmatic GAPDH gene in the symbiotic dinoflagellate genus Symbiodinium and its related species (the order Suessiales): Possible lateral gene transfer between two eukaryotic algae, dinoflagellate and euglenophyte. Protist. 2003;154(3):443-54.

81. Rowan R, Whitney SM, Fowler A, Yellowlees D. Rubisco in marine symbiotic dinoflagellates: form II enzymes in eukaryotic oxygenic phototrophs encoded by a nuclear multigene family. Plant Cell. 1996;8(3):539-53.

82. Rosic NN, Pernice M, Rodriguez-Lanetty M, Hoegh-Guldberg O. Validation of housekeeping genes for gene expression studies in Symbiodinium exposed to thermal and light stress. Mar Biotechnol. 2011;13(3):355-65.

83. Leggat W, Seneca F, Wasmund K, Ukani L, Yellowlees D, Ainsworth TD. Differential responses of the coral host and their algal symbiont to thermal stress. PLoS One. 2011;6(10):e26687.

84. Rosic NN, Pernice M, Dove S, Dunn S, Hoegh-Guldberg O. Gene expression profiles of cytosolic heat shock proteins Hsp70 and Hsp90 from symbiotic dinoflagellates in response to thermal stress: possible implications for coral bleaching. Cell Stress Chaperones. 2011;16(1):69-80.

85. Boldt L, Yellowlees D, Leggat W. Measuring Symbiodinium sp. gene expression patterns with quantitative real-time PCR. In: Proceedings of the 11th International Coral Reef Symposium: 2008; Fort Lauderdale, FL, USA, 2008;118-22.

86. Barshis DJ, Ladner JT, Oliver TA, Palumbi SR. Lineage specific transcriptional profiles of Symbiodinium spp. unaltered by heat stress in a coral host. Mol Biol Evol. 2014;31(6):1343-52.

87. Milos P, Morse D, Hastings J. Circadian control over synthesis of many Gonyaulax proteins is at a translational level. Naturwissenschaften. 1990;77(2):87-9.

88. Okamoto OK, Robertson DL, Fagan TF, Hastings JW, Colepicolo P. Different regulatory mechanisms modulate the expression of a dinoflagellate iron-superoxide dismutase. J Biol Chem. 2001;276(23):19989-93.

89. Mayfield AB, Hsiao Y-Y, Chen H-K, Chen C-S. Rubisco expression in the dinoflagellate Symbiodinium sp. is influenced by both photoperiod and endosymbiotic lifestyle. Mar Biotechnol. 2014;16(4):1-14.

90. Baumgarten S, Bayer T, Aranda M, Liew YJ, Carr A, Micklem G, et al. Integrating microRNA and mRNA expression profiling in Symbiodinium microadriaticum, a dinoflagellate symbiont of reef-building corals. BMC Genomics. 2013;14(1):704.

91. Voolstra CR, Sunagawa S, Schwarz JA, Coffroth MA, Yellowlees D, Leggat W, et al. Evolutionary analysis of orthologous CDNA sequences from cultured and symbiotic 
dinoflagellate symbionts of reef-building corals (Dinophyceae: Symbiodinium) Comp Biochem Physiol D Genomics Proteomics. 2009:4(2):67-74.

92. Logan DDK, LaFlamme AC, Weis VM, Davy SK. Flow-cytometric characterization of the cell-surface glycans of symbiotic dinoflagellates (Symbiodinium spp.). J Phycol. 2010;46(3):525-33.

93. Benson DA, Karsch-Mizrachi I, Lipman DJ, Ostell J, Sayers EW. GenBank. Nucleic Acids Res. 2010;38 suppl 1:D46-51.

94. UniProt_Consortium. Update on activities at the Universal Protein Resource (UniProt) in. Nucleic Acids Res 2013. 2013;41(D1):D43-7.

95. Fawal N, Li Q, Savelli B, Brette M, Passaia G, Fabre M, et al. PeroxiBase: a database for large-scale evolutionary analysis of peroxidases. Nucleic Acids Res. 2013;41(D1):D441-4.

96. Untergasser A, Cutcutache I, Koressaar T, Ye J, Faircloth BC, Remm M, et al. Primer3 - New capabilities and interfaces. Nucleic Acids Res. 2012;40(15):e115.

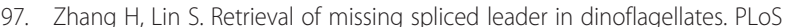
One. 2009;4(1):e4129.

98. Thompson JD, Gibson TJ, Plewniak F, Jeanmougin F, Higgins DG. The ClustalX windows interface: Flexible strategies for multiple sequence alignment aided by quality analysis tools. Nucleic Acids Res. 1997;24:4876-82.

99. Altschul SF, Gish W, Miller W, Myers EW, Lipman DJ. Basic local alignment search tool. J Mol Biol. 1990;215(3):403-10.

100. Salamov AA, Nishikawa T, Swindells MB. Assessing protein coding region integrity in CDNA sequencing projects. Bioinformatics. 1998;14(5):384-90.

101. Käll L, Krogh A, Sonnhammer EL. Advantages of combined transmembrane topology and signal peptide prediction-the Phobius web server. Nucleic Acids Res. 2007:35 suppl 2:W429-32.

102. Emanuelsson O, Nielsen H, Brunak S, von Heijne G. Predicting subcellular localization of proteins based on their N-terminal amino acid sequence. J Mol Biol. 2000;300(4):1005-16.

103. Fankhauser N, Mäser P. Identification of GPI anchor attachment signals by a Kohonen self-organizing map. Bioinformatics. 2005;21(9):1846-52.

104. Pierleoni A, Martelli PL, Casadio R. PredGPI: a GPI-anchor predictor. BMC Bioinform. 2008;9(1):392.

105. Zhang Y. I-TASSER server for protein 3D structure prediction. BMC Bioinform. 2008;9(1):40.

106. Abascal F, Zardoya R, Posada D. ProtTest: selection of best-fit models of protein evolution. Bioinformatics. 2005;21(9):2104-5.

107. Felsenstein J. Confidence limits on phylogenies: An approach using the bootstrap. Evolution. 1985:39:783-91.

108. Hillis DM, Bull JJ. An empirical test of bootstrapping as a method for assessing confidence in phylogenetic analysis. Syst Biol. 1993:42:182-92.

109. Guindon S, Gascuel O. A simple, fast and accurate algorithm to estimate large phylogenies by maximum likelihood. Syst Biol. 2003;52(5):696-704.

110. Andersen $\mathrm{CL}$, Jensen $\mathrm{J}$, Ørntoft TF. Normalization of real-time quantitative reverse transcription-PCR data: a model-based variance estimation approach to identify genes suited for normalization, applied to bladder and colon cancer data sets. Cancer Res. 2004;64(15):5245-50.

111. Pfaffl MW, Horgan GW, Dempfle L. Relative expression software tool (REST@) for group-wise comparison and statistical analysis of relative expression results in real-time PCR. Nucleic Acids Res. 2002:30(9):e36.

\section{Submit your next manuscript to BioMed Central and take full advantage of:}

- Convenient online submission

- Thorough peer review

- No space constraints or color figure charges

- Immediate publication on acceptance

- Inclusion in PubMed, CAS, Scopus and Google Scholar

- Research which is freely available for redistribution

Submit your manuscript at www.biomedcentral.com/submit 